\title{
Categorias de Análise Musical e Modelagem Física como Análise do Timbre
}

\author{
Categories of Musical Analysis and Physical Modeling as Analysis of \\ Timbre
}

\author{
Rodolfo Coelho de Souza \\ Universidade de São Paulo
}

\begin{abstract}
Resumo: Este artigo traz uma reflexão sobre as categorias de análise que são usadas para obras de diferentes poéticas e estilos. Lembramos que a taxonomia foi primeira categoria de análise a ser usada. Continua sendo muito empregada, como por exemplo na análise harmônica tradicional. A segunda categoria de análise é a funcional, empregada por exemplo na análise harmônica riemanniana. Essa categoria se reinventa na estratégia da engenharia reversa como a que é usada na contagem da série dodecafônica. A terceira categoria é da hermenêutica que também envolve estratégias heurísticas. Ela tem sido a base de diversas teorias analíticas recentes como a das Tópicas e da Narratividade. Finalmente reconhecemos como quarta categoria a estratégia da modelagem, aplicada às obras cuja análise é resistente às categorias anteriores. Propomos que a análise do timbre é particularmente afeita à estratégia da modelagem, reconhecendo que a técnica da modelagem física por meios digitais oferece uma perspectiva promissora nessa direção.
\end{abstract}

Palavras-chave: Análise Musical; Taxonomia; Engenharia Reversa; Hermenêutica; Modelagem de Timbre

\begin{abstract}
This article offers a reflection about the categories of analysis employed for works of different poetics and styles. We remind that taxonomy was the first category of analysis to be used. It remains very useful, as it is used, for instance, in traditional harmonic analysis. The second is the category of functional analysis, employed, for instance, in the Riemannian harmonic analysis. This category reinvents itself in the strategy of reverse engineering, as it is used to count twelve-tone series. The third category is the hermeneutics that also involves heuristics strategies. It has been the basis of many recent analytical theories as the Topic and the Narrative. Finally, we recognize modeling as a fourth strategy of analysis, which can be applied to pieces that resist the approach of other analytical categories. We propose that the analysis of timbre is particularly keen to the modeling strategy, reminding that the physical modeling technique by digital means offers a promising perspective in this direction.
\end{abstract}

Keywords: Musical Analysis; Taxonomy; Reverse Engineering; Hermeneutics; Modeling of Timbre 
MUSICA THEORICA Revista da Associação Brasileira de Teoria e Análise Musical 2019, v. 4, n. 1, p. 62-97 - Journal of the Brazilian Society for Music Theory and Analysis@ TeMA 2019 - ISSN 2525-5541

\section{Introdução: Meta-Análise da Análise Musical}

Ao propor uma reflexão sobre o campo de Análise Musical encontramos a princípio quatro categorias de análise que apresentam características diferentes em função de seus métodos e objetivos. Designamos essas categorias como Taxonômica, Funcional ou Engenharia Reversa, Hermenêutica, e finalmente, Modelagem. A diferenciação entre essas categorias nem sempre é muito clara. Na verdade, uma análise pode envolver mais de uma categoria. Mas há casos em que a natureza do objeto requer uma determinada abordagem e determinadas categorias de análise se revelam inviáveis. Nosso propósito neste trabalho é refletir sobre essas diversas categorias de análise, finalizando com um problema complexo e atual que é a análise do timbre, um tópico de interesse para a música contemporânea (entendida aqui como a música dos séculos XX e XXI). A análise do timbre pode ficar constrangida a limites estreitos com metodologias das três primeiras categorias elencadas. Insights mais produtivos aparecem com a quarta categoria de análise, a Modelagem.

\subsection{Categoria das Análises Taxonômicas}

Diversos métodos clássicos de análise musical encaixam-se nessa categoria. Como se sabe, o desenvolvimento do pensamento taxonômico foi essencial para a crescimento das ciências naturais. Ciências como Botânica, Zoologia e Anatomia Humana tem sua base primordial no modelo taxonômico, ou seja, num processo que busca reconhecer e agrupar elementos dispersos e num estágio subsequente postular uma hierarquia na sua organização. $\mathrm{O}$ pensamento taxonômico não se preocupa com o funcionamento de um sistema que descreve. Preocupa-se com reconhecer os componentes desse sistema e nomear as classes de objetos que compartilham certas características. Em seguida estaremos habilitados a identificar a pertinência de um indivíduo ou objeto a uma classe postulada.

A figura 1 mostra um brinquedo para crianças pequenas que é baseado no pensamento taxonômico. Uma base de madeira com diversos encaixes, que são formas vazias (literalmente, não uma metáfora!), é apresentada para a criança. Em seguida ela recebe uma porção de peças coloridas. Sua tarefa, que requer um pensamento inteligente não tão elementar quanto pode parecer, é combinar a forma e o tamanho dos objetos concretos com as formas vazias. Dependendo do estágio do desenvolvimento da criança, a solução é encontrada de forma 
COELHO de SOUZA, R. Categorias de Análise Musical e Modelagem Física como Análise do Timbre

concreta, por tentativa e erro. Mais adiante, esse tipo de experiência concreta servirá para o desenvolvimento do pensamento abstrato que permite à criança associar a forma vazia com a forma concreta.

Note-se que haveria pelo menos três propriedades que permitem diferenciar os objetos entre si: a forma (triângulo, círculo, retângulo e quadrado, retângulo), o tamanho (grande e pequeno) e a cor (amarelo, vermelho, azul e verde). Duas dessas propriedades são relevantes para a taxonomia proposta pelo brinquedo: a forma e o tamanho. A cor, a princípio, é irrelevante para a solução, mas vemos que os elementos pertencentes a cada forma têm também a mesma cor. Ou seja, as propriedades de forma e de cor configuram uma única categoria. Essa associação certamente ajuda a criança pequena na solução do problema pois, em vez de lidar com três propriedades diferentes, ela precisa manipular apenas duas. O quebra-cabeças sem dúvida ficaria mais difícil para uma criança pequena se houvesse uma mistura aleatória de cores entre as peças.

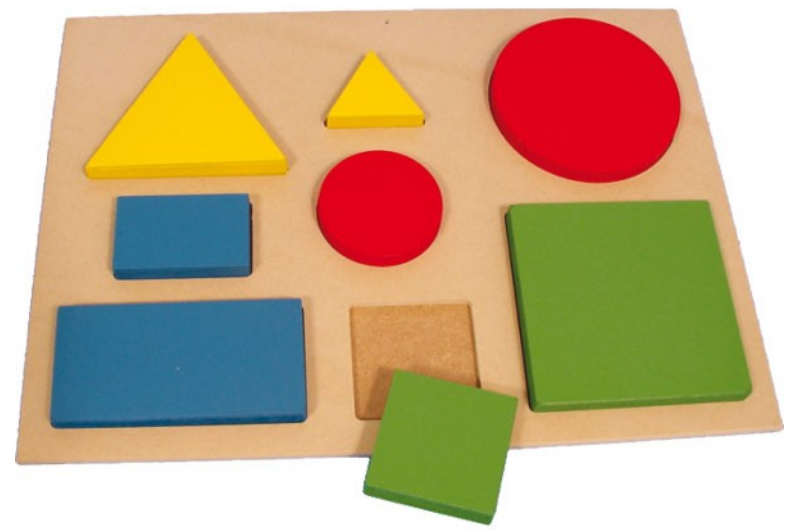

Figura 1: Brinquedo de encaixe de peças em base com formas em baixo relevo (imagem de quebra-cabeça da linha Brink Jogos da Editora Simque)

A escolha de um brinquedo para ilustrar o pensamento taxonômico não foi fortuita. As ciências taxonômicas, apesar de muitas vezes demandarem um árduo trabalho de identificação, classificação e nomeação, são muitas vezes consideradas fora de moda, obsoletas, a despeito de imprescindíveis.

A Análise Musical frequentemente opera no nível taxonômico. Consideremos, por exemplo, a análise harmônica tonal pelo sistema de graus e também a análise de formas musicais do estilo clássico. O objetivo de ambas é identificar a posição de um determinado objeto musical num sistema classificatório construído a priori pelas ciências da Análise Harmônica e da 
MUSICA THEORICA Revista da Associação Brasileira de Teoria e Análise Musical 2019, v. 4, n. 1, p. 62-97 - Journal of the Brazilian Society for Music Theory and Analysis@ TeMA 2019 - ISSN 2525-5541

Análise Formal. Ou seja, o propósito da análise é encaixar um objeto em uma das formas vazias da matriz de possibilidades do sistema.

Consideremos o Exemplo 1. Para uma análise formal, podemos fazer uma simples observação preliminar que indicaria que as vozes se movimentam com parcimônia diatônica, e às vezes cromática no contralto e no baixo, ou com notas repetidas, como na longa sustentação de pedal no soprano. O uso de homofonia homorrítmica e a conservação do quarteto vocal nos permite delimitar a pertinência desse fragmento a uma peça coral (por exemplo a uma frase de moteto ou de música sacra), ou a um tema de música instrumental que se aproprie do estilo coral. Como percebemos que nesse trecho existe uma única cadência no fim do excerto, podemos afirmar que sua forma corresponde à de uma "frase musical". Dado que o fragmento é muito curto, nossa classificação formal estanca aqui, mas já podemos perceber que as hipóteses foram cogitadas somente dentro de um sistema de possibilidades dado pela teoria das formas musicais. Em outras palavras, o que buscamos foi uma classificação taxonômica.

Considerando a análise harmônica do Exemplo 1 podemos afirmar também que ela não revela nada além da identificação da tipologia de cada acorde dentre as limitadas possibilidades oferecidas pelo sistema tonal, como dado a priori. Ou seja, o sistema tonal equivale à chapa de madeira com formas vazias escavadas do brinquedo da Figura 1 e cada acorde é uma réplica concreta positiva de um dos tipos ideais daquela estrutura que é usada então como sistema classificatório. Novamente, um procedimento clássico do pensamento taxonômico.

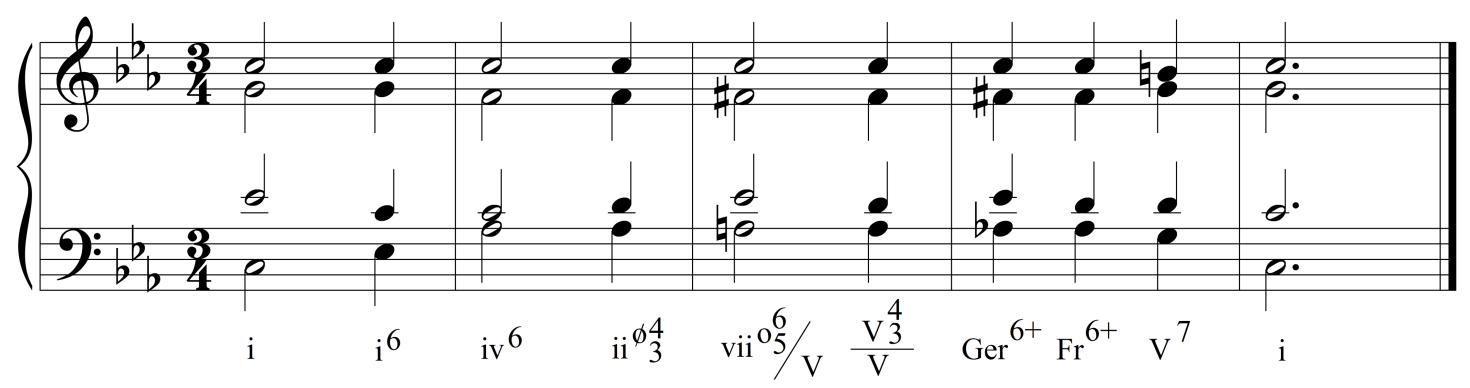

Exemplo 1: Análise de fragmento musical com cifras de harmonia tradicional de graus

Subindo um degrau no processo de abstração poderíamos argumentar que uma gramática é, na sua essência, uma estrutura taxonômica que estuda as regras de correlações válidas num determinado sistema. Num artigo clássico, Roads e Wieneke (1979) mapearam diversos sistemas analíticos musicais que operam por 
COELHO de SOUZA, R. Categorias de Análise Musical e Modelagem Física como Análise do Timbre

princípios taxonômicos baseados em gramáticas. Aquele estudo seminal sugeriu, entre outras coisas, que seria possível desenhar programas computacionais de análise de harmonia tonal bastante eficientes, pois um computador é capaz de realizar com rapidez a comparação de características dos acordes reais de uma música com seus modelos abstratos no sistema tonal. Nos quarenta anos que se passaram desde então, dezenas de projetos implementaram essa ideia. Apenas para mencionar um deles, de um pesquisador vinculado à plataforma comercial "Chordify", destacamos o artigo de Bas De Haas et al. (2014).

Por outro lado, se observarmos a progressão cromática de quatro prédominantes da dominante (5o ao 8a acordes) que emprega duas versões diferentes de acordes de sexta aumentada, podemos cogitar que seria mais provável encontrar essa passagem numa peça de Mozart do que numa de Bach, dada a frequência com que passagens cromáticas desse tipo ocorrem na obra de um e de outro. Esse raciocínio não pertence mais ao campo de uma análise taxonômica. Esta hipótese pertence à próxima categoria de modelos de análise.

\subsection{Categoria das Análises Funcionais e de Engenharia Reversa}

As ciências naturais progrediram gradativamente de conhecimentos classificatórios baseados em características superficiais para conhecimentos funcionais que explicavam o mecanismo interno dos objetos. Exemplos paradigmáticos dessa evolução são a Genética, que passou de uma ciência que trabalhava apenas sobre Fenótipos para um novo estágio, o dos Genótipos. Na Medicina, a Anatomia avança para a Fisiologia, e as descrição das partes do organismo são complementadas pelo entendimento de seu funcionamento.

Esse paradigma científico se espalhou naturalmente para as outras áreas do conhecimento. Nas ciências humanas, a teoria da música embarca na mesma empreitada. Podemos lembrar que no século XIX, acompanhando a onda funcionalista, Hugo Riemann propõe uma nova visão da teoria da harmonia inspirada no paradigma funcionalista. Rehding (2003, p. 38) aponta como a teoria da harmonia funcional riemanniana, baseada num pressuposto dualista, abriu caminho para o entendimento da harmonia cromática a partir do pressuposto de que a harmonia tonal obedece ao paradigma lógico da progressão T-S-D-T, postulada desde sua tese de doutorado (Riemann, 1874). No Exemplo 2 vemos como uma análise funcionalista reinterpreta os graus do Exemplo 1 em termos das funções que os acordes exercem no sistema tonal. Enfatizemos que não há 
MUSICA THEORICA Revista da Associação Brasileira de Teoria e Análise Musical 2019, v. 4, n. 1, p. 62-97 - Journal of the Brazilian Society for Music Theory and Analysis@ TeMA 2019 - ISSN 2525-5541

nenhuma contradição entre as duas análises. A primeira informa que "coisa" é cada acorde no sistema taxonômico baseado nos graus da escala e a segunda diz que "função" exercem aquelas mesmas coisas num sistema funcionalista baseado na lógica das progressões tonais postulada por Riemann.

Uma análise funcionalista, numa acepção rigorosa, não deveria depender de interpretações subjetivas. Deveria obedecer à lógica inerente ao sistema que seria plenamente mecanicista. As complicações que surgem na análise funcional riemanniana derivam do princípio dualista herdado de Hauptmann que Riemann abraçou com entusiasmo. Esse princípio introduz o problema de uma hermenêutica entre alternativas polares. Por exemplo, devemos considerar o terceiro grau de uma tonalidade maior como sendo uma dominante relativa ou uma tônica anti-relativa? Esse problema demanda recorrer à terceira categoria que propusemos, a das análises hermenêuticas. Mas não votaremos a este exemplo porque podemos encontrar outros casos que ilustram melhor a questão.

Note-se ainda que os métodos analíticos estão sempre sujeitos a revisões e novas codificações. As cifras de harmonia funcional usadas no Exemplo 2 tem diferenças consideráveis em relação àquelas propostas originalmente por Riemann. Elas na verdade seguem a prática comum atual nas culturas que adotam esse sistema em suas escolas, como em partes da Alemanha e da Áustria. No Brasil há diversas vertentes, mas, neste caso, optamos por Krämer (1997).

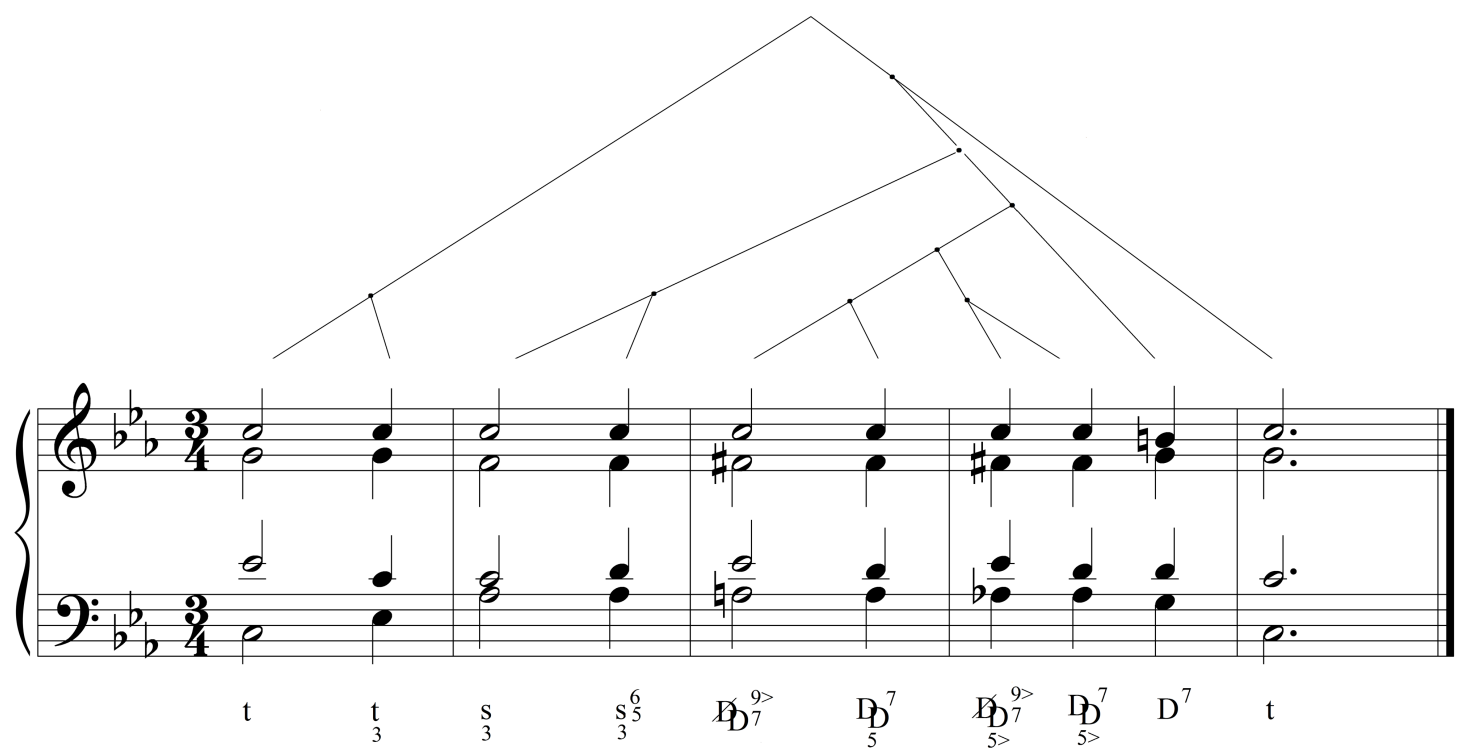

Exemplo 2: Análises funcional riemanniana e gerativa de Lerdahl do mesmo excerto 
COELHO de SOUZA, R. Categorias de Análise Musical e Modelagem Física como Análise do Timbre

As análises funcionais, mesmo de um objeto aparentemente inequívoco, como uma progressão harmônica, podem receber formulações diversas. A mesma progressão que no Exemplo 1 foi analisada por graus, e no Exemplo 2 foi analisada por funções harmônicas, pode ser analisada pela lógica da gramática gerativa de Chomsky, como o fez Lerdahl $(1883,2001)$. Não se trata de uma proposta que refuta o funcionalismo harmônico de Riemann, ao contrário, é uma teoria que procura generalizar o princípio a partir da teoria de Chomsky que propõe reconhecer a sintaxe como um fenômeno universal compartilhado por todas as linguagens, a princípio verbais, mas que Lerdahl propõe valer também para a sintaxe da música tonal. Embora não seja clara a pertinência desse método analítico ao campo das teorias funcionalistas, pois ela também envolve um nível hermenêutico, consideramos que ela equivale do ponto de vista heurístico à teoria da harmonia funcional riemanniana e, portanto, é predominantemente funcionalista.

Menos claramente funcionalistas, são as análises que seguem o paradigma da engenharia reversa. Esse conceito vem da área tecnológica, em que existe essa prática usual de desmontar um dispositivo para entender como ele funciona. Justamente porque o objetivo é compreender um funcionamento, estamos no campo das análises funcionalistas. Fazemos isso, por exemplo, para descobrir como opera uma máquina para poder copiar sua estrutura numa réplica.

Existem diversos métodos de composição no século vinte que não procuram justificar seus princípios com base nas leis naturais da acústica. Por isso não se pode analisar seu processo sintático com base em regras taxonômicas e funcionais universais. Um bom exemplo disso é o método dodecafônico da Segunda Escola de Viena, pelo menos na versão que ficou consagrada pelo breve tratado de Křenek (1940). Qual é o objetivo da análise que faz a chamada "contagem da série"? Esse tipo de análise não revela nada a respeito de um possível sentido latente da obra, e nem mesmo a pertinência de sua linguagem a um modelo de sintaxe universal. Revela apenas como funciona a aplicação do método dodecafônico naquela peça. 


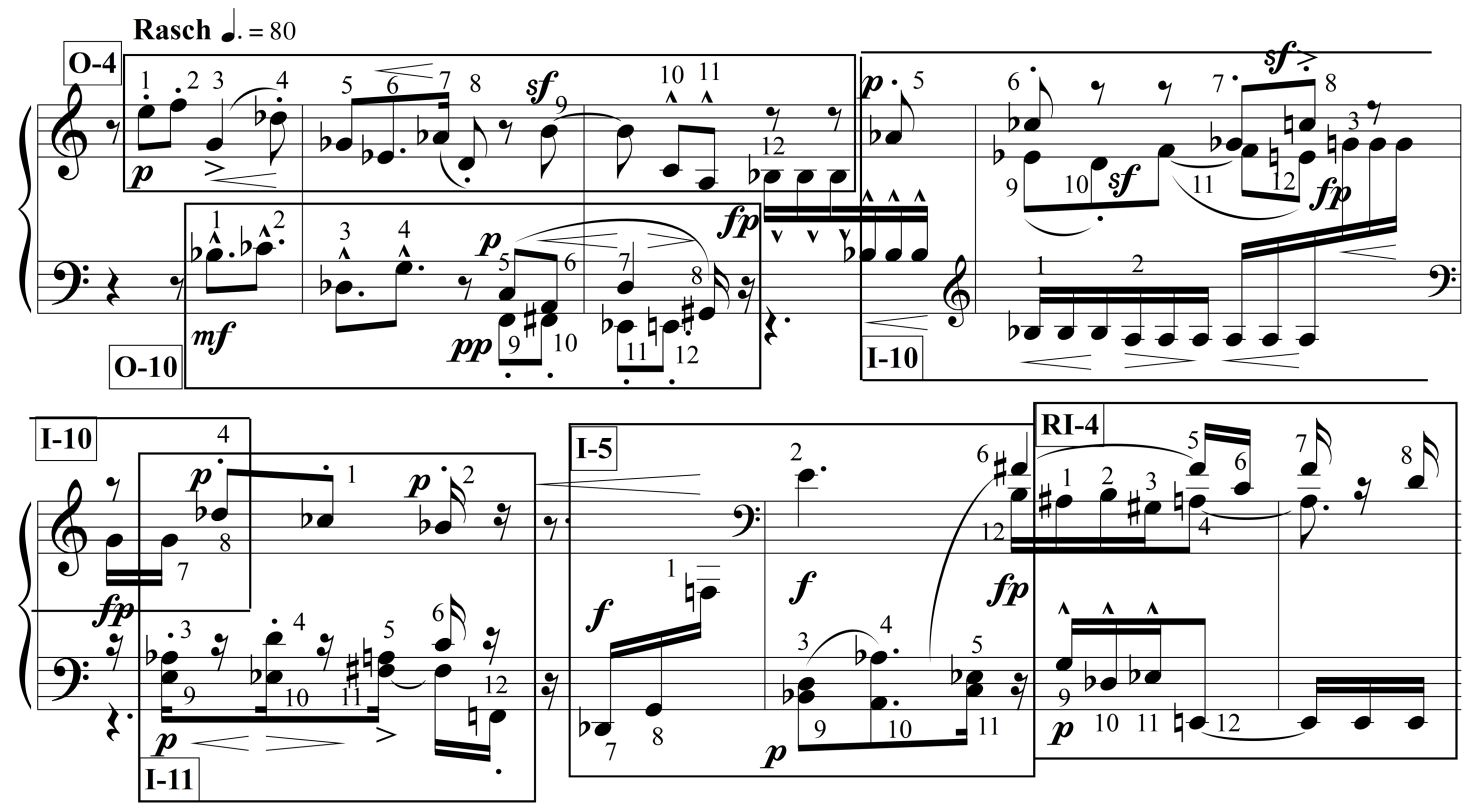

Exemplo 3: Análise dodecafônica do início do Präludium da Suite Op. 25 de Schönberg

O Exemplo 3 mostra um trecho de uma análise, de nível básico, do início do Präludium da Suite Op. 25 de Schönberg. Dado o autor e o período histórico, obviamente o pressuposto da análise é que se trata de uma peça dodecafônica. Presume-se que, logo a princípio, seja exposta uma série de doze sons que seria possível encontrar por um processo de tentativa e erro, característico das análises por engenharia reversa. De fato, encontramos logo no início, na voz superior, uma série que parece ser a série geradora da obra (ver Schönberg 1963, p. 171):

$\mathrm{O}-4=\{\mathrm{E}, \mathrm{F}, \mathrm{G}, \mathrm{D} b, \mathrm{G} b, \mathrm{E} b, \mathrm{~A} b, \mathrm{D}, \mathrm{B}, \mathrm{C}, \mathrm{A}, \mathrm{B} b\}$

As séries subsequentes serão reconhecidas, também por tentativa e erro, como resultantes de variações isomórficas da série original, ou seja, séries obtidas por operações de transposição, inversão ou retrogradação. De fato, a análise esquematizada no Exemplo 3 nos permite entender o mecanismo que foi usado para produzir a música, mas nada além disso. Esse tipo de compreensão nos permite, porém, reproduzir o processo e gerar infinitas variações que funcionariam como réplicas do estilo dodecafônico da peça. Na verdade, a análise dodecafônica tem dificuldade de superar esse nível de engenharia reversa funcionalista, por isso o método dodecafônico foi muitas vezes acusado de automatismo mecânico e desqualificado como mero exercício de estruturação vazia. Reiteramos que análises dodecafônicas, como a do Exemplo 3, hoje contribuem pouco. Para acrescentar algum conhecimento relevante, 
COELHO de SOUZA, R. Categorias de Análise Musical e Modelagem Física como Análise do Timbre

possivelmente precisaríamos incorporar descobertas heurísticas da categoria analítica seguinte.

Uma informação útil que poderia ser acrescentada seria uma análise comparativa com obras de outros autores. Esse tipo de resultado foi alcançado por Straus (2009) ao comparar a música do dodecafonistas norte-americanos com a música da escola vienense, para concluir que nunca houve uma ortodoxia dodecafônica, como se costuma acreditar. Na verdade, basta comparar as regras postuladas para o contraponto dodecafônico por Křenek para se chegar a esse mesmo resultado. Se fossemos medir pelas regras de Křenek (que parecem se conformar bem à música de Webern), a música de Schönberg, criador do dodecafonismo, seria considerada "não ortodoxa". Bastaria constatar que Schönberg diversas vezes divide a série de 12 notas em conjuntos menores com 4 e 6 notas e faz uma parte da série sobrepor-se a outra parte, interrompendo a linearidade da série, um procedimento não descrito por Křenek.

Afirmamos que este tipo de análise de música dodecafônica equivale a um processo de engenharia reversa. Isso tem uma implicação adicional. Essa análise poderia, então, subsidiar o projeto de um algoritmo que produzisse automaticamente resultados similares. Projetos de composição algorítmica dependem sempre de codificações específicas que explicitem detalhadamente as regras gerativas de um determinado estilo descobertas por reversão analítica. $O$ projeto de pesquisa de uma vida inteira desenvolvido por David Cope (vide, por exemplo, Cope 2005), exemplifica com clareza esse problema. Cope demonstra que a o processo de análise e síntese reversa é condicionado pelo entendimento das regras de formação de um estilo. Esse é provavelmente o resultado mais interessante que produzem as análises que através de engenharia reversa descrevem o funcionamento de obras paradigmáticas.

Há ainda um ponto importante a ressaltar no caso da análise da peça de Schönberg. Foi relativamente simples desenvolver a análise do Exemplo 3 porque as regras gerativas usuais da música dodecafônica são de domínio comum. Mesmo na década de 1940, quando o sistema dodecafônico ainda era novidade, um compositor brasileiro como Cláudio Santoro, distante dos proponentes do sistema para ter acesso a informações de primeira mão, foi capaz de usar a análise reversa (de Alban Berg) para entender os procedimentos do sistema e replicá-lo em suas obras. Isso demonstra que a análise reversa no sistema dodecafônico é feita num nível bastante transparente. De fato, no Exemplo 3, a série básica 
MUSICA THEORICA Revista da Associação Brasileira de Teoria e Análise Musical 2019, v. 4, n. 1, p. 62-97 - Journal of the Brazilian Society for Music Theory and Analysis@ TeMA 2019 - ISSN 2525-5541

aparece, como em muitas obras desse estilo, na melodia da voz superior no início da peça. O resto da análise é uma montagem de um quebra-cabeças simples porque a chave para a decodificação estava pendurada na porta de entrada.

Para outras análises reversas nem sempre há transparência e chamaremos esses casos de análise reversa de objeto opaco. Um bom exemplo é a dificuldade que se encontra na análise das obras do serialismo de Darmstadt. Uma das mais celebradas façanhas é a análise de Lev Koblyakov (1990) de Le marteau sans maître (1952-55) de Pierre Boulez. Koblyakov enfatiza a dificuldade da tarefa:

A natureza especial e a dificuldade de analisar música serial são o resultado de sua organização complexa. O problema é que, além da serialização de todos os parâmetros, códigos numéricos são usados, os quais ajudam no desenvolvimento hierárquico do sistema serial. Além disso, com Boulez a série geral de uma composição é principalmente um organismo gerador de uma rede de séries derivadas, e usualmente ela não tem um papel direto na música. Por isso o investigador deve ter pelo menos alguns esboços do próprio compositor, senão ele terá que realizar uma tarefa de incrível complexidade. (Koklyakov 1990, p. 3).

Numa nota de rodapé, Koblyakov comenta que a ausência de análises de obras seriais de Stockhausen e Nono se deve a essa dificuldade de acesso a esboços que pudessem ajudar a elucidar o processo. Alega, porém, não ter tido acesso aos esboços do Marteau de Boulez. Entretanto, em outro parágrafo, Koblyakov reconhece que só conseguiu realizar a análise devido à ajuda do compositor. Ou seja, Boulez passou para Koblyakov as múltiplas chaves das diversas portas de acesso ao mecanismo altamente complexo dessa música serial, altamente opaca à análise reversa.

Para termos uma ideia da tarefa hercúlea, vejamos um excerto da análise de Koblyakov, enfocando apenas os dez primeiros compassos do primeiro movimento Avant "d'artisanat furieux" (Ex. 4). 

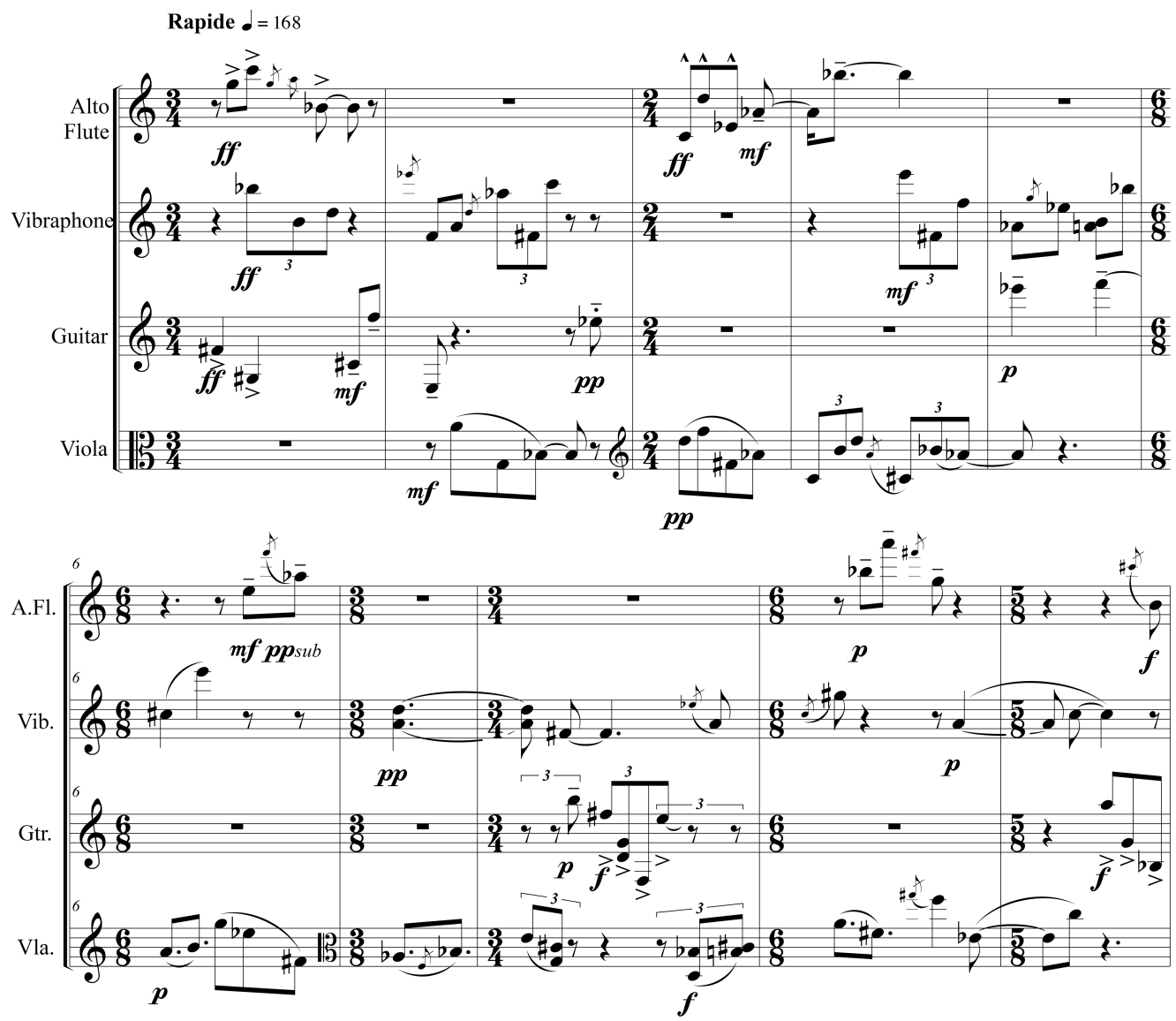

Exemplo 4: Dez primeiros compassos de Le Marteau sans Maître de Pierre Boulez

Como afirmou Koblyakov, as tentativas de reconhecer a série geradora da música a partir de uma leitura direta da partitura não revelam nada. A série usada nesse fragmento (e há outras séries para outras partes da música) está encriptada por um complexo processo de geração de conjuntos derivados pela chamada "multiplicação de Boulez", um processo de replicar os intervalos de um fragmento da série em todas as notas de outro fragmento da série.

A série, que é dodecafônica, usada por Boulez para compor esse fragmento é mostrada no Exemplo 5. Podemos supor, pelo que afirmou Koblyakov, que Boulez forneceu essa série ao analista.

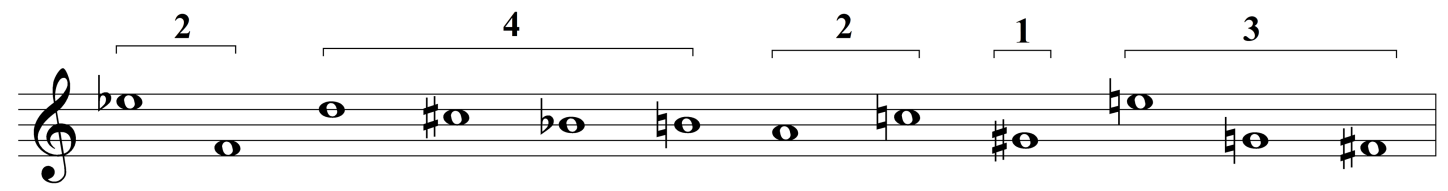

Exemplo 5: Série usada no início de Le marteau sans maître para gerar outras derivações (adaptado de Koblyakov 1990, p. 4) 
MUSICA THEORICA Revista da Associação Brasileira de Teoria e Análise Musical 2019, v. 4, n. 1, p. 62-97 - Journal of the Brazilian Society for Music Theory and Analysis@ TeMA 2019 - ISSN 2525-5541

No processo idiossincrático que Boulez usou para compor essa obra, a série é dividida sucessivamente em diversos agrupamentos. A primeira divisão é feita em conjuntos de 2, 4, 2, 1 e 3 notas, conforme marcado no Exemplo 5. A seguir o compositor construiu matrizes que resultam da multiplicação da série pelos diversos conjuntos recortados na primeira linha e reconfigurados com as multiplicações nas sucessivas colunas. O resultado produziraá diversas matrizes, sendo que a primeira é mostrada no Exemplo 6. A numeração das linhas e colunas da matriz foi modificada em relação a Koblyakov para facilitar a compreensão da análise mostrada no Exemplo 7.

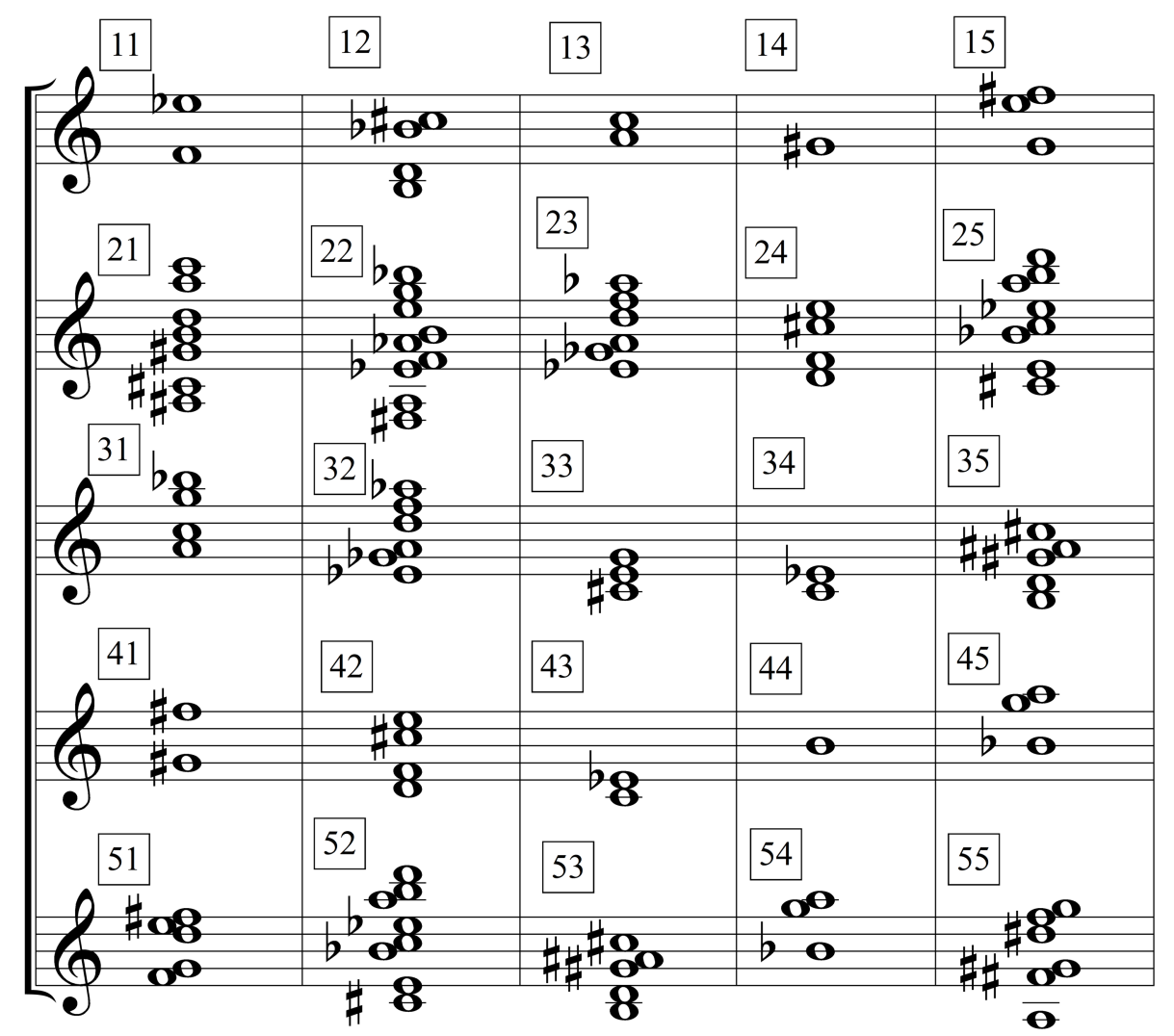

Exemplo 6: Primeira matriz do primeiro ciclo do início de Le marteau sans maître (adaptado de Koblyakov 1990, p. 137)

Com base nos conjuntos identificados 11 a 55 dessa matriz Koblyakov identificou suas ocorrências na partitura, conforme mostrado no Exemplo 7. Os conjuntos que identificamos no Exemplo 7 tem pequenas divergências em relação à análise de Koblyakov, mas isso é irrelevante. As diferenças decorrem da busca de Koblyakov por identificar os percursos sistemáticos de leitura da matriz que Boulez sugeriu. Pela análise de Koblyakov, Boulez leu a matriz seguindo 
COELHO de SOUZA, R. Categorias de Análise Musical e Modelagem Física como Análise do Timbre

caminhos sistemáticos nas diagonais, à semelhança do modo como se calcula determinantes de matrizes, um procedimento que era familiar para quem teve sólida formação em matemática como Boulez. Uma das dificuldades importantes que dificultam na engenharia reversa chegar-se à série original da qual foram geradas as derivações, é que os conjuntos 11 a 55 são conjuntos não-ordenados. Ou seja, o serialismo usado por Boulez nessa obra está muito longe de ser serial porque não há linearidade e ordenação nos materiais que podem ser muito mais bem descritos como formações harmônicas encadeadas. $O$ princípio de conservação das alturas nessas formações verticais tampouco é relevante, porque prevalece o princípio da equivalência de oitava, ou seja, as notas são tratadas como classes de alturas, tal como na teoria dos conjuntos de Forte. O problema fica ainda mais complexo quando lembramos que a segmentação revelada por Koblyakov no Exemplo 7 não pode ser presumida a priori, nem pode ser deduzida pela observação da partitura ou por critérios perceptivos. Portanto, ela só pode ser identificada a partir dos dados da matriz do Exemplo 6.

Note-se ainda que esta obra é paradigmática no estilo do serialismo integral, de modo que todos os outros parâmetros musicais também foram serializados por Boulez. Ou seja, dinâmicas, durações, instrumentação, etc, tudo segue um planejamento rigoroso de derivações seriais. Entretanto não é nosso propósito nos debruçarmos aqui sobre esses tópicos, mesmo porque a análise serial completa está detalhada no trabalho de Koblyakov (1990). Pretendemos apenas demonstrar que a engenharia reversa do algoritmo inventado por Boulez para compor essa obra é de tal complexidade, ou seja é um mecanismo tão opaco, que somente com o conhecimento prévio das chaves da codificação é possível desvendar a criptografia da obra.

No prefácio da publicação do seu trabalho, escrito quinze anos depois de ter defendido a tese de doutoramento em que propôs a análise, Koblyakov reconhece que desvendou posteriormente muitos outros aspectos da obra que não havia percebido na primeira tentativa, mas que isso implicaria em reescrever o trabalho. Isso indica que ele se deu de conta que o gigantesco esforço de revelar todos os detalhes do processo serial de Boulez dava conta apenas do mecanismo de geração da obra, isto é, do algoritmo passo a passo que Boulez inventou e seguiu rigorosamente na composição. Entretanto esse nível de análise revela muito pouco sobre como a obra é ouvida, ou seja, que sentidos perceptivos ela produz. A próxima categoria aborda esse terceiro tipo de objetivo analítico. 


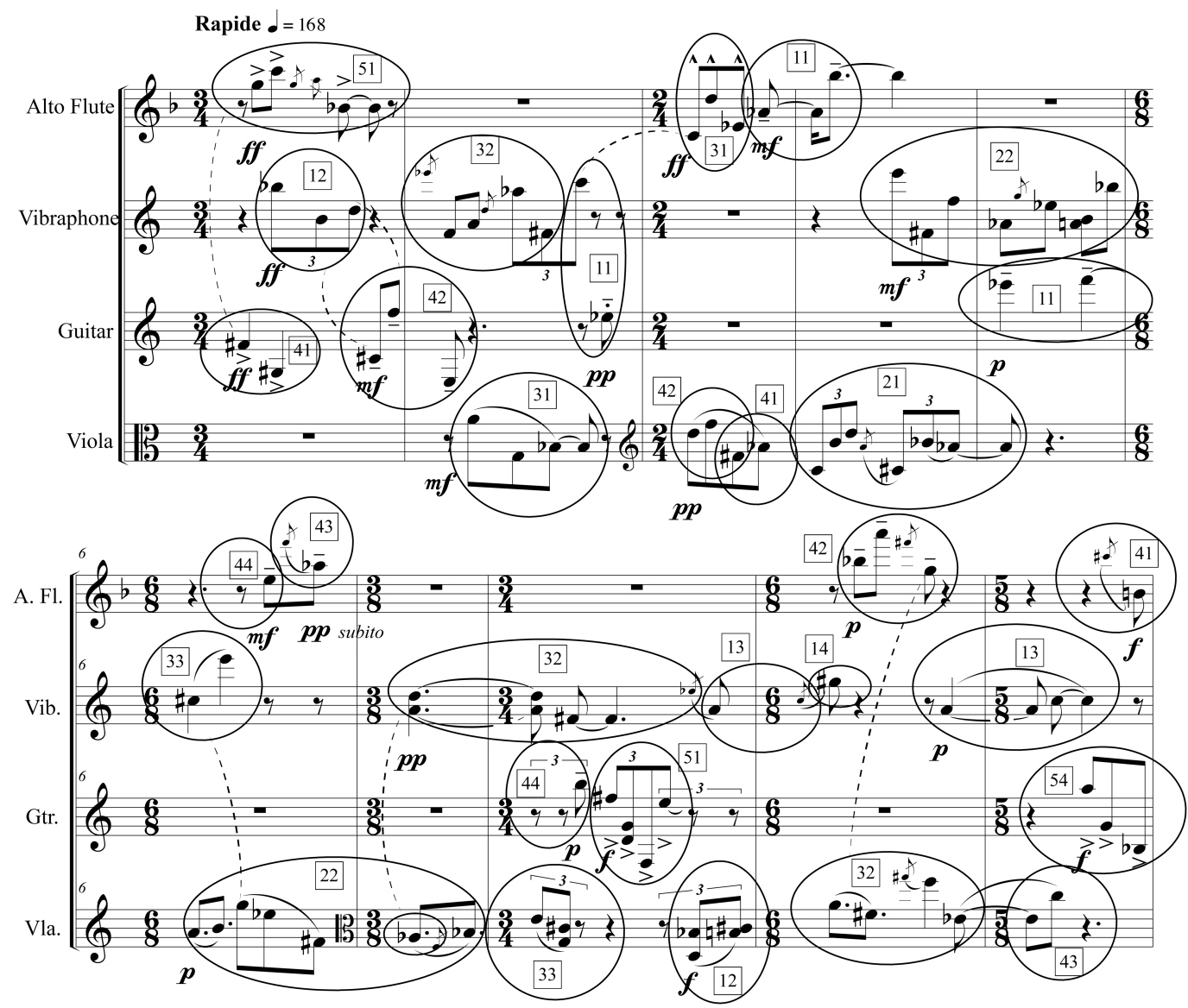

Exemplo 7: Análise do serialismo bouleziano do início de Le marteau sans maître (adaptado de Koblyakov 1990, p. 205)

\subsection{Categoria das Análises Hermenêuticas}

Nas duas categorias anteriores, a correção das afirmações feitas sobre os objetos analisados sempre pode ser verificada por critérios objetivos. Isso não significa, por exemplo, que não se possa propor uma outra análise para a peça de Boulez, mas não se pode questionar a segmentação proposta por Koblyakov porque ela é congruente com as premissas do processo de multiplicação serial de Boulez. Nesse sentido não há ambiguidades nem subjetivismo nas análises propostas. O modelo é dado a priori e a análise simplesmente reconhece a congruência do objeto com o modelo.

Entretanto há outros tipos de processos analíticos em que a decisão não é unívoca. Consideremos o exemplo da Figura 2. Temos uma estante com oito caixas que foi projetada para guardar objetos de modo a separá-los por suas características. Vamos supor que os objetos a guardar sejam sempre cubos e que 
COELHO de SOUZA, R. Categorias de Análise Musical e Modelagem Física como Análise do Timbre

eles apareçam com duas variáveis, cor e tamanho. Considere a seguir que nosso objetivo seja classificar e guardar o cubo que é mostrado à esquerda.
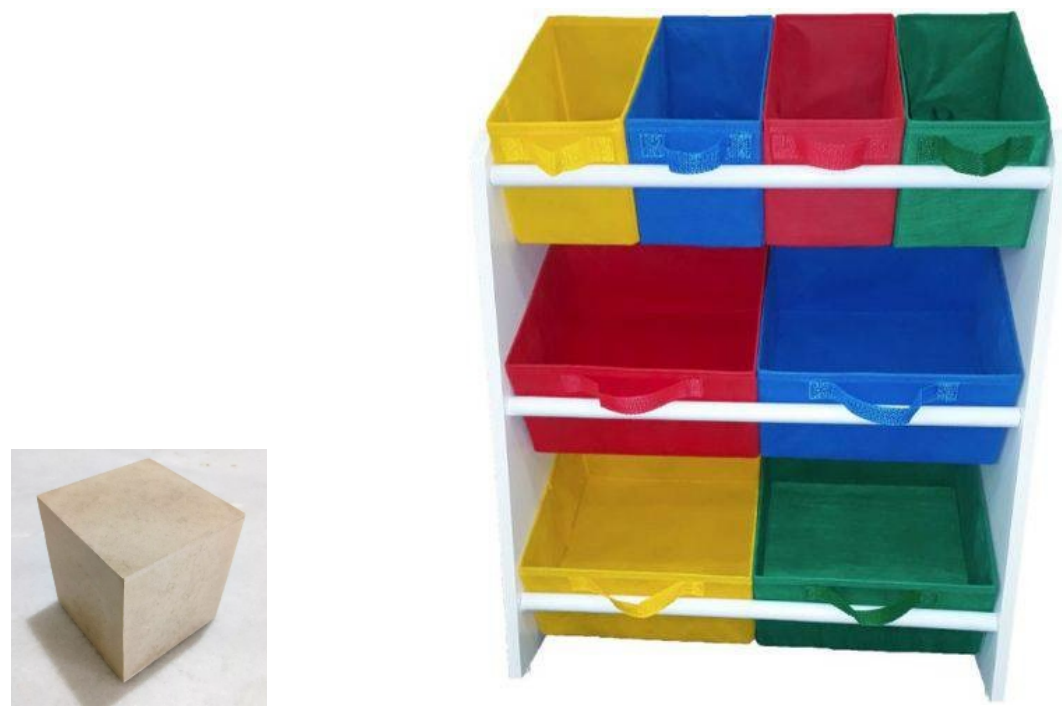

Figura 2: Como classificar este cubo na estante de organização de objetos?

O tamanho do cubo é grande demais para ser acomodado em uma das quatro caixas da prateleira superior, mas as caixas das duas prateleiras inferiores podem acomodá-lo. Até aqui nosso raciocínio seguiu o paradigma taxonômico. No passo seguinte precisamos decidir em qual das quatro caixas inferiores o cubo deve ser guardado. A decisão seria automática se o cubo fosse vermelho, azul, amarelo ou verde. Porém esse cubo não se encaixa adequadamente em nenhuma das categorias disponíveis. Como escolher, então, uma das caixas?

Obviamente não há uma única solução possível e nem sequer uma que seja inequivocamente a mais correta. O problema é a ambiguidade do objeto. Para tomar uma decisão é necessário postular um critério que justifique a escolha. Podemos, por exemplo, argumentar que a palidez do cubo é apenas o resultado da cor amarela ter perdido o brilho. Assim a caixa amarela seria o destino adequado para o cubo. Ou podemos decidir armazenar o cubo branco na caixa azul por um gosto estético pessoal. Estamos no terreno da ambiguidade em que é necessário estipular os princípios que sustentem uma interpretação hermenêutica dos motivos da decisão.

Diversas teorias de análise musical operam no nível hermenêutico. Observemos que uma interpretação hermenêutica normalmente é acompanhada 
MUSICA THEORICA Revista da Associação Brasileira de Teoria e Análise Musical 2019, v. 4, n. 1, p. 62-97 - Journal of the Brazilian Society for Music Theory and Analysis @ TeMA 2019 - ISSN 2525-5541

por um achado heurístico. Todos conhecemos aquele momento do "estalo" em que uma ideia se revela e permite a resolução do problema.

A Teoria dos Conjuntos, em si, é essencialmente taxonômica, pois seu objetivo é fazer um inventário da tipologia de conjuntos de notas existentes no universo cromático, das suas propriedades internas e das relações entre conjuntos. Ainda que se possa considerá-la complexa, ela é plenamente determinística. Entretanto, uma análise baseada na teoria dos conjuntos é necessariamente hermenêutica porque necessita de um passo intermediário que não é dado a priori, qual seja, a segmentação do discurso em conjuntos discretos. A segmentação é, por sua natureza intrínseca, o resultado de uma interpretação, de uma visão heurística. Lembremos que o problema da segmentação tem sido vivamente debatido, e suscitou, por exemplo, o alentado trabalho de Dora Hanninen (2012) sobre o tema. Numa perspectiva oposta, pode-se argumentar que, do ponto de vista de uma análise automatizada através de inteligência artificial, seria possível reduzir o aspecto heurístico a uma busca por padrões classificatórios conhecidos. Entretanto, essa discussão ampliaria o problema para muito além dos limites da análise musical, pois significaria admitir a possibilidade de redutibilidade da própria natureza do pensamento heurístico.

Para ilustrar o problema, efetuamos uma análise segundo a teoria dos conjuntos dos mesmos sete compassos iniciais de Le marteau sans maître de Boulez (vide Exemplo 8). É o mesmo trecho em que, no Exemplo 7, mostramos sua gênese a partir da matriz de multiplicação de uma série, conforme propôs Koblyakov. Comparando as duas análises verifica-se facilmente que seus resultados não apresentam nenhuma equivalência.

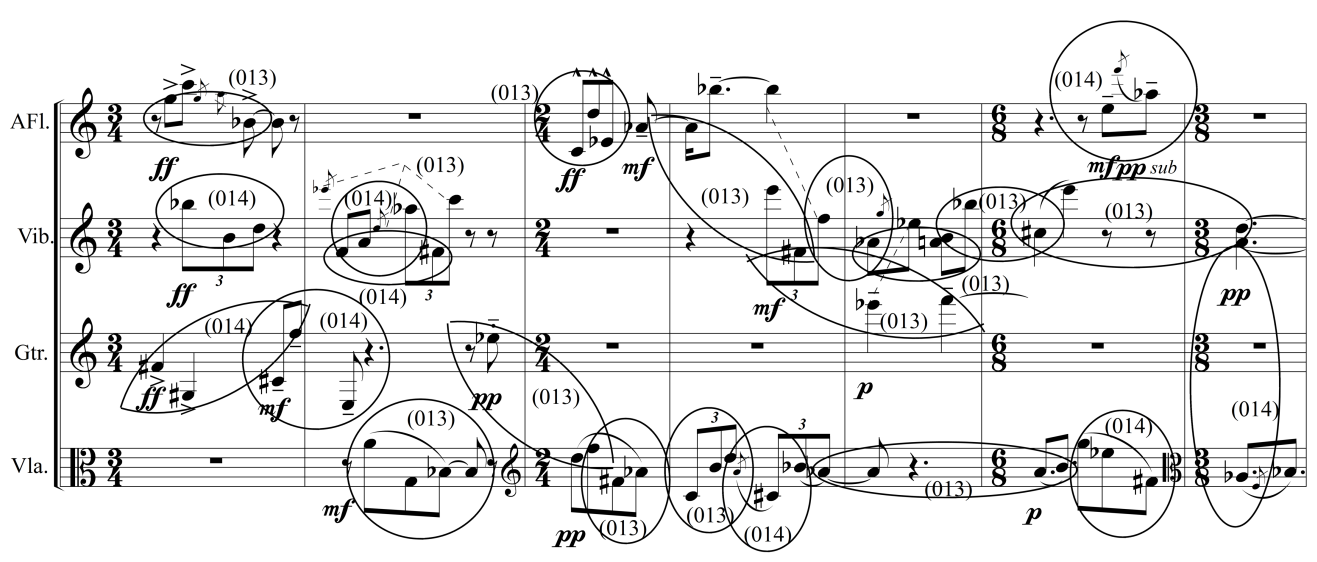

Exemplo 8: Análise pela teoria dos conjuntos do início de Le marteau sans maître 
COELHO de SOUZA, R. Categorias de Análise Musical e Modelagem Física como Análise do Timbre

A análise mostrada no exemplo 8 segmentou a partitura em conjuntos de três notas que pertencem a apenas dois conjuntos elementares de Forte, quais sejam os tricordes 3-2:(013) e 3-3:(014). A preocupação dessa análise foi demonstrar a coesão da obra em torno de duas sonoridades levemente contrastantes, pois seriam formadas ambas por um semitom e uma terça, uma terça menor no conjunto 3-2 e uma maior no 3-3. Portanto o objetivo dessa análise seria revelar uma organicidade que não é possível vislumbrar na análise serial do Exemplo 7. Pelo contrário, aquela análise descrevia uma explosão da coerência serial que parecia impossível de ser reconciliada com qualquer unidade perceptiva. Porém, um tipo de unidade é recuperado nessa análise de conjuntos.

Essa discrepância não significa uma contradição, como se uma estivesse certa e a outra errada. O processo da engenharia reversa do Exemplo 7 pretendeu demonstrar como a peça teria sido construída. A análise hermenêutica do Exemplo 8 quis mostrar uma maneira de entender o resultado perceptivo. Uma operou segunda a categoria funcional, a outra segundo a categoria heurística/hermenêutica.

Outras teorias em voga que pertencem ao universo da hermenêutica são as teorias das Tópicas, da Intertextualidade e da Narratividade. Robert Hatten foi quem mais claramente percebeu que a natureza dessas análises as coloca no campo da hermenêutica. A explicação que Hatten apresenta para o conceito de análise hermenêutica é brilhante na sua concisão e precisão:

Hermenêutica: o termo origina-se nos métodos de interpretação da Bíblia e na longa tradição da crítica literária; foi apropriada no século XX por Kretschman (1902) para a significação musical expressiva. Neste trabalho o termo se refere a uma abordagem interpretativa de qualquer significado que vá além do puramente estrutural ou "sintático" ("implicacional", funcional), baseando-se em evidências de qualquer fonte relevante para (abdutivamente) reconstruir estratégias interpretativas (estilisticamente guiadas) (Hatten 1996, p. 290).

Atente-se para um detalhe na frase de Hatten. Diz ele: "baseando-se em evidências..." como sendo a condição necessária para a abdução (formulação de uma hipótese) interpretativa. Este é o calcanhar de Aquiles do processo hermenêutico, em outras palavras, a possibilidade de que ele se desvirtue em "achismo", na fantasia subjetiva, que só pode ser evitada mantendo-se o foco na objetividade das evidências. O próprio termo "hermenêutica" foi rejeitado pela análise musicológica durante parte significativa do século vinte porque esteva 
MUSICA THEORICA Revista da Associação Brasileira de Teoria e Análise Musical 2019, v. 4, n. 1, p. 62-97 - Journal of the Brazilian Society for Music Theory and Analysis@ TeMA 2019 - ISSN 2525-5541

contaminado pela prática do século dezenove de uma hermenêutica sem amarras propriamente analíticas. Essa prática privilegiava a livre associação de ideias, impressões sensoriais e imagens subjetivas na construção de discursos cuja intenção era fazer o elogio de uma obra musical. Esse estilo de análise persiste no século vinte, às vezes mesclado com alguma objetividade, como se pode ver depreender do seguinte trecho da crítica de Souza Lima, sobre a peça Lenda do Caboclo de Villa-Lobos:

Evoca, com a maior simplicidade de escritura, o nosso sertanejo no seu viver tranquilo, entrosado na natureza que tudo lhe proporciona [...]. Para evocar ainda mais a atmosfera de calma de nossas matas, Villa-Lobos, com uma nota que vibra sobre o balancear dos acordes, nos lembra o canto da juriti. (Souza Lima, apud Versolato 2008, p. 80). ${ }^{1}$

As metáforas do "sertanejo tranquilo", da "calma da mata", dos "acordes que balançam" e do "canto da juriti" são imagens poéticas provavelmente sugeridas pelo título da peça, mas dizem muito pouco da música em si e serviriam para comentar muitas outras peças de Villa-Lobos. Uma análise não pode se ater à recepção estética do ouvinte no nível estésico, conforme objeta Nattiez, mesmo porque haveria uma recepção diferente para cada ouvinte. Enfatizamos que a análise hermenêutica moderna, embora possa expressar uma posição subjetiva, deve estar embasada em evidências objetivas.

Para ilustrar esse dilema entre o objetivo e o subjetivo na análise musical hermenêutica podemos lembrar o seminário que se realizou em torno da Sonata Tempestade de Beethoven publicado pela Universidade de Leuven (Bergé, 2009). Diversos analistas de grande reputação, como Bergé, Burnham, Burstein, Caplin, Hamilton, Hatten, Hepokoski, Kinderman, Rothstein, Seaton e Moortele analisam a mesma obra sob perspectivas analíticas diferentes partindo dos trabalhos seminais de Dahlhaus (1989, p. 13) e Schmalfeldt (2011, p. 39-49). O conjunto dos problemas que eles abordam é muito complexo e extenso para ser tratado neste contexto, mesmo que resumidamente. Vou me ater a um ponto que ilustra a questão da hermenêutica. O início da Sonata, mostrado no Exemplo 9, justapõe um arpejo em tempo lento e uma progressão tensa em andamento rápido. O que "quer dizer" essa frase? É uma introdução? Ou já é o primeiro

\footnotetext{
${ }^{1}$ Original publicado em Comentários sobre a obra pianística de Villa-Lobos. Rio de Janeiro: MEC Museu Villa-Lobos, 1969
} 
tema? Ou trata-se de uma introdução de dois compassos com o tema começando no terceiro compasso?

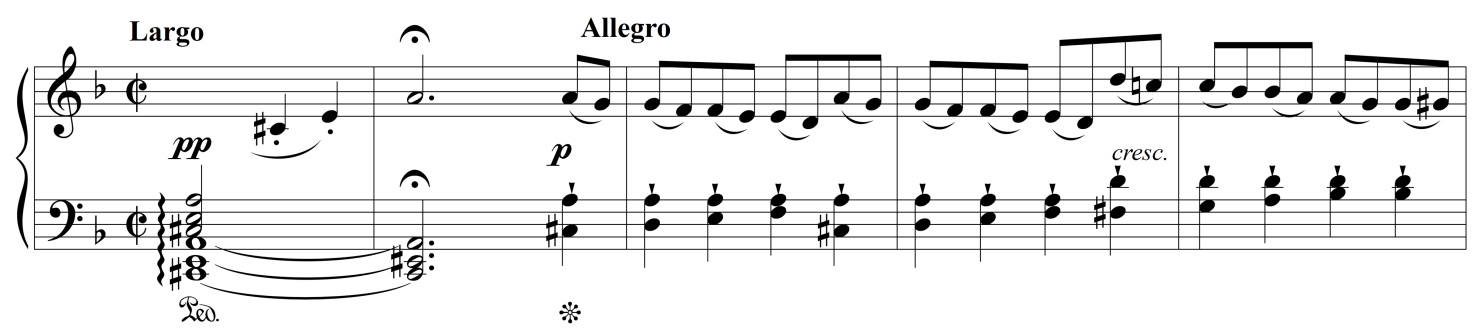

Exemplo 9: Sonata n. 17, op. 31 n. 2, Tempestade, c. 1-6, de Beethoven

Uma leitura hermenêutica atualizada não buscaria atribuir um significado metafórico a esta passagem, mas procuraria indícios nos elementos funcionais e tópicos para dar uma resposta às questões acima aventadas. A solução clássica, que todos os autores mencionados partilham de algum modo, considera que a chave deve ser encontrada na recapitulação (vide Ex. 10). O material do início reaparece ali com uma inserção de quatro compassos que é característico de uma linha vocal de recitativo. Isso esclarece que toda a passagem inicial já era de fato o primeiro tema, composto com dois materiais contrastantes, o primeiro em tópica de recitativo e o segundo em tópica de Sturm und Drang. Schmalfeldt nos esclarece que a significação é sempre retroativa. $O$ futuro esclarece o passado. Hatten nos esclarece que o limite da hermenêutica é o compartilhamento do signo em uma determinada cultura. Recitativo e tempestade só fazem sentido para quem conhece gêneros e estilos oriundos da ópera séria.

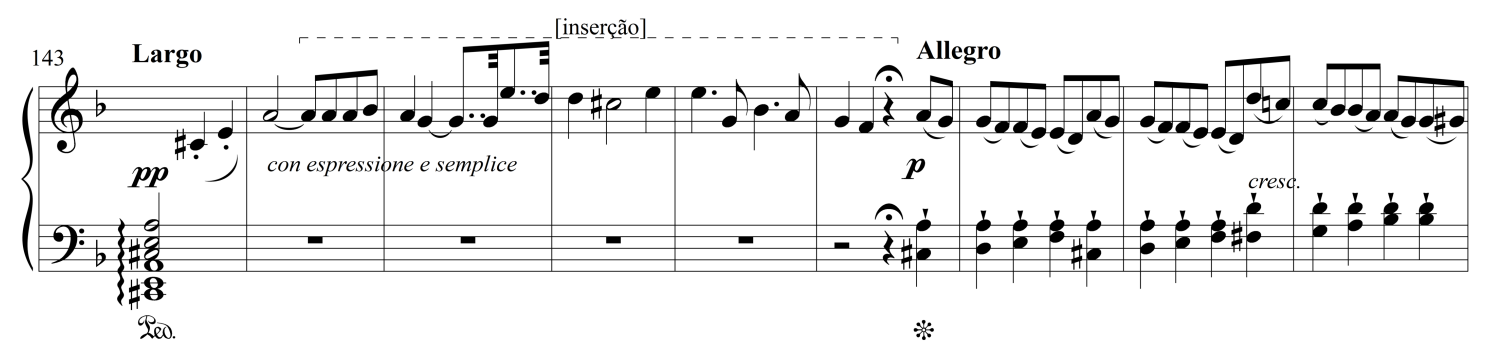

Exemplo 10: Sonata n. 17, op. 31 n. 2, Tempestade, c. 143-151, de Beethoven

Numa outra vertente, há trabalhos analíticos na linha heurística que parecem extrapolar as proporções razoáveis entre estudo do objeto e pura especulação, como se a criatividade hermenêutica não precisasse derivar da análise do objeto, mas ganhasse vida própria. $\mathrm{O}$ melhor exemplo dessa tendência talvez seja o artigo "Set Theory, Derivation and Transformational Structures in 
MUSICA THEORICA Revista da Associação Brasileira de Teoria e Análise Musical 2019, v. 4, n. 1, p. 62-97 - Journal of the Brazilian Society for Music Theory and Analysis @ TeMA 2019 - ISSN 2525-5541

Analizing Webern's Opus 10, Number 4" de David Lewin publicado postumamente em 2007 no livro Musical Form and Transformation.

A partitura de Webern analisada por Lewin é mostrada no Exemplo 11. Como vemos ocupa uma única página, com seis compassos e a execução consome em torno de 20 segundos. Em contraste com a concisão de Webern, o artigo de Lewin tem 29 páginas, atravessa diversas etapas de processos transformacionais, mesmo só tratando do parâmetro alturas, ainda que durações, dinâmicas e timbres exerçam papéis relevantes na peça.

IV.

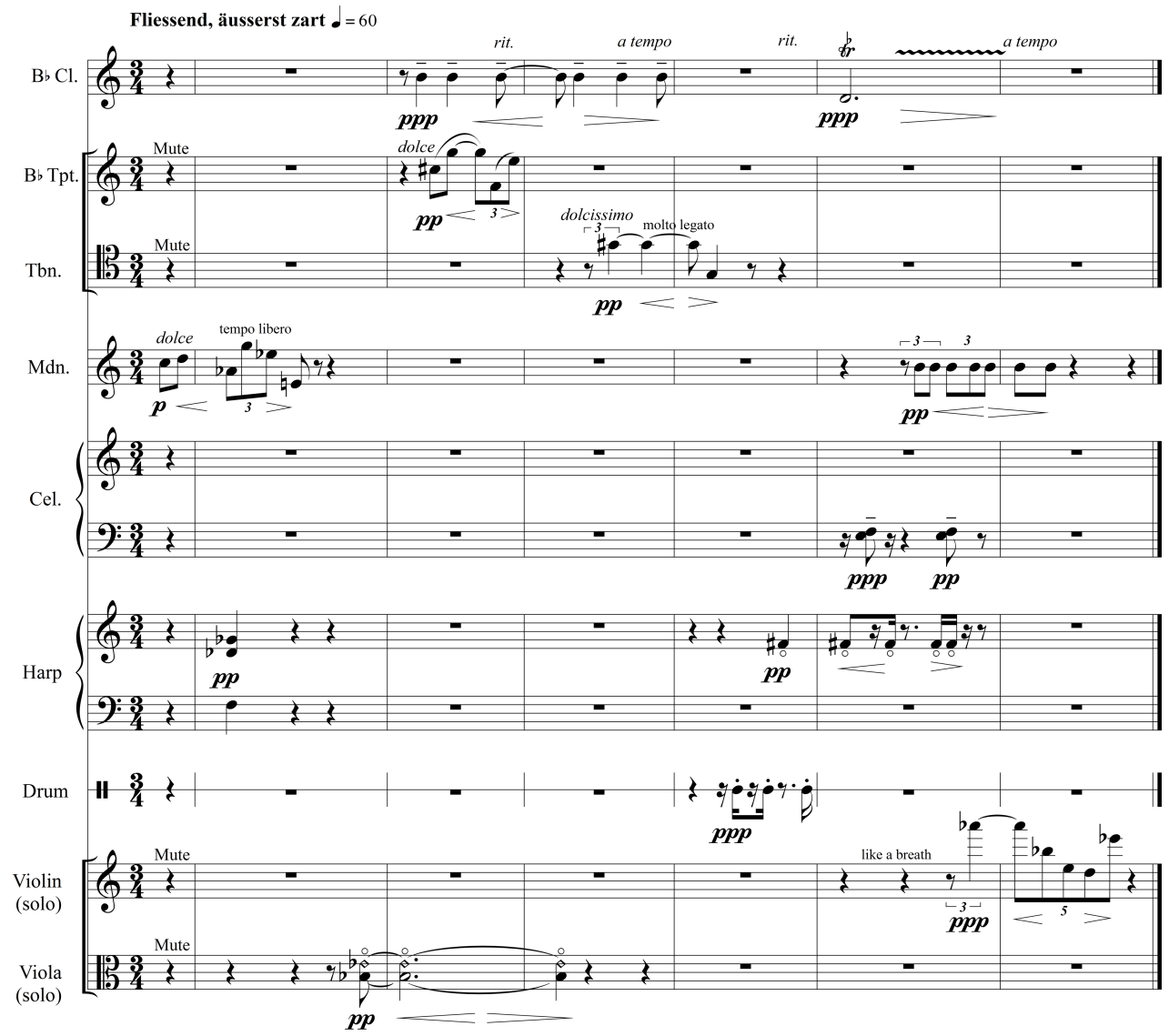

Exemplo 11: Webern op. 10 n. 4 para conjunto misto

O primeiro estágio da análise de Lewin parte de um trabalho anterior de Allen Forte que oferece uma interpretação heurística dentro das expectativas normais das análises com a teoria dos conjuntos. Lewin resume esse resultado no esquema do Exemplo 12, reconhecendo um material básico $\mathrm{H}$, da classe de conjuntos 6-Z43, seu complemento $\mathrm{h}$, da classe 6-Z17, e as transformações isomórficas indicadas por $\mathrm{T}=$ transposição e $\mathrm{L}=$ inversão. 


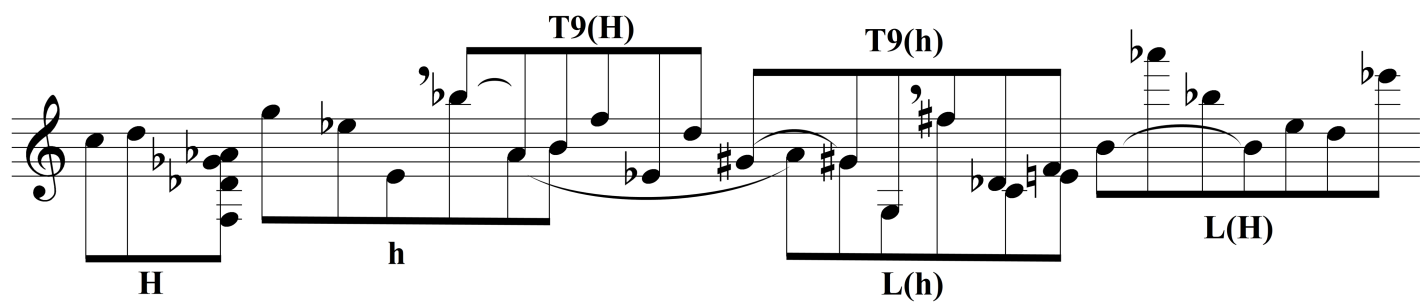

Exemplo 12: Primeiro estágio da análise de Lewin do op. 10 n. 4 de Webern (adaptado de Lewin 2007 p. 69, Example 3.2)

Como dissemos, a análise de Lewin prossegue por diversos estágios (em minha contagem, sete) de teorizações sobre transformações e finalmente o esquema do Exemplo 13 resume os achados analíticos de Lewin em sua forma mais geral e abstrata. Nesse esquema I significa inversão em Mi ou Sib; J significa inversão em Ré/Mi b ou SolÆ/Lá; e K significa inversão em Fá\#/Sol ou Dó/Réb.

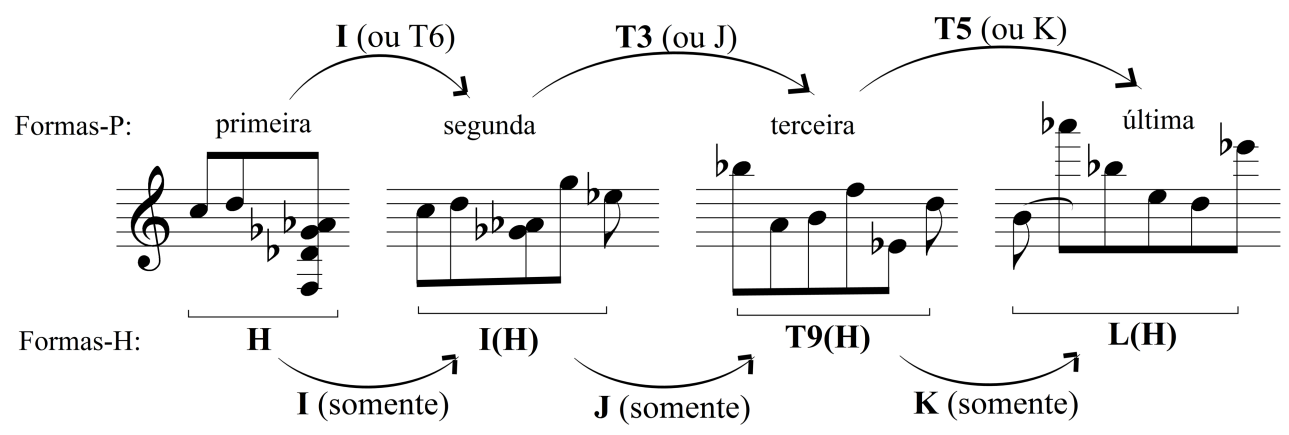

Exemplo 13: Último estágio da análise de Lewin do op. 10 n. 4 de Webern (adaptado de Lewin 2007, p. 85, Example 3.19)

Esse estilo de análise, característico dos anos 1980, sofreu críticas principalmente da corrente da Nova Musicologia que lamentava o afastamento dos aspectos perceptuais e contextuais. Não obstante, o trabalho de Lewin prosseguiu sendo referencial e respeitado porque, por mais que sua imaginação analítica pareça se distanciar da obra e crie uma narrativa estrutural autônoma, sua lógica é impecável e suas conclusões brilhantes. Na defesa dessas chamadas "ficções analíticas", Marion Guck (1994) lembra que nossa percepção de uma obra pode ser profundamente transformada e enriquecida por narrativas analíticas que funcionam como reflexos paralelos à superfície do discurso.

\subsection{Categoria das Análises por Modelagem}

A quarta e última categoria analítica que propomos neste estudo é a da Modelagem. Ela surge como uma necessidade das poéticas musicais a partir da 
MUSICA THEORICA Revista da Associação Brasileira de Teoria e Análise Musical 2019, v. 4, n. 1, p. 62-97 - Journal of the Brazilian Society for Music Theory and Analysis@ TeMA 2019 - ISSN 2525-5541

segunda metade do século vinte. Vimos como a análise do serialismo de Boulez não permite mais a decodificação de uma funcionalidade e é praticamente indevassável por engenharia reversa, a menos que as chaves sejam fornecidas exmachina. Outras obras de autores daquele período ou recentes serão ainda mais resistentes a qualquer daquelas duas estratégias. Por exemplo, peças que sejam compostas por algoritmos que usem o acaso e cálculos probabilísticos em sua geração são inacessíveis à recuperação passo a passo do processo que as produziu visto que não obedecem a uma lógica causal. Como analisá-las então?

Keller e Ferneyhough (2004) apresentam uma alternativa engenhosa que é o recurso à modelagem. Muitas obras musicais recentes utilizam a formaprocesso na sua organização. Para dar conta de sua análise a modelagem busca entender o processo com que foram produzidas e não o resultado específico do processo, visto que ele pode ser considerado uma entre muitas alternativas que o processo poderia ter gerado. Outras obras, que utilizem formas-abertas, isto é, com partes sujeitas a escolhas pelo intérprete gozam do mesmo status de imprevisibilidade do resultado, mas a análise por modelagem seria tautológica porque a partitura manifesta o próprio modelo das variantes possíveis. Entretanto há certos níveis, mesmo em obras geradas deterministicamente, cuja análise pode se beneficiar da estratégia da modelagem, como veremos adiante.

Keller lembra que obras baseadas no fenômeno do processo são frequentes em "performances artísticas, instalações sonoras, música algorítmica e várias formas de sistemas de som ambiental". No artigo mencionado ilustra essa solução analítica modelando a peça ST/10-1 080262 (1967) de Xenakis que é uma das primeiras obras compostas por computador da história da música. A análise por modelagem dessa obra parte de uma partitura e da gravação de uma execução que também servirão como objeto de comparação para validar o modelo. Um dos aspectos críticos do processo é escolher os parâmetros que serão modelados. Embora Keller se concentre no parâmetro das alturas na modelagem proposta no artigo, ele sugere que a timbre também poderia ser modelado. Para tanto oferece um modelo das propriedades de excitação e ressonância dos timbres, com uma análise preliminar taxonômica das categorias empregadas pelo compositor naquela obra, como mostramos na Figura 3. 


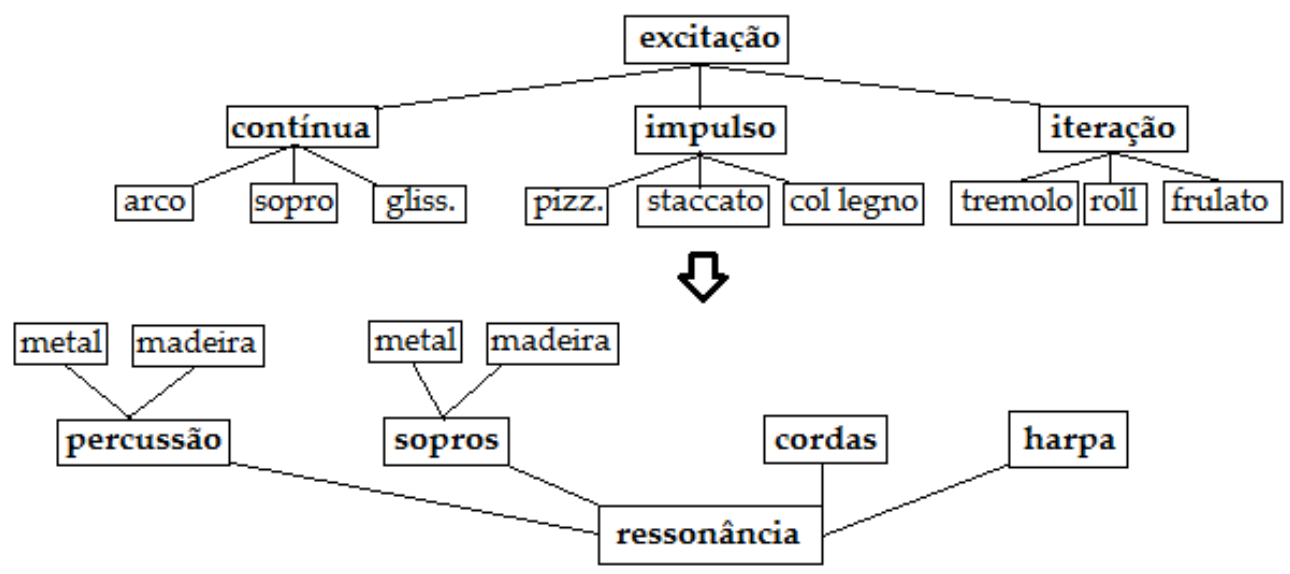

Figura 3: Taxonomia dos timbres orquestrais usados na obra ST/10-1 080262, de Xenakis na parametrização da modelagem analítica de Keller (adaptado de Keller e Ferneyhough 2004, p. 166, Fig. 3)

A proposta de estratégia analítica por modelagem que Keller e Ferneyhough sugeriram para os timbres orquestrais da obra de Xenakis, ainda que não a tenham desenvolvido como análise específica do campo timbrístico, sugeriu-me que a estratégia poderia ser ampliada para a análise do timbre como parâmetro isolado, especialmente nas obras contemporâneas em que as variantes do timbre, geradas por exemplo por técnicas estendidas, sejam um ponto focal da estética da linguagem do compositor. Em seguida expandiremos esse tópico e proporemos como uma das estratégias possíveis de análise do timbre, a modelagem física na síntese digital de instrumentos virtuais.

\section{Análise do Timbre}

Uma crítica, recorrentemente feita à teoria e à musical, é que elas só se preocupam com o parâmetro das alturas. É fato que a quantidade de estudos que focam na questão das alturas é mais numerosa do que a dos que consideram outros parâmetros. Entretanto, tem havido um aumento de estudos que levam em consideração os outros parâmetros, principalmente as durações, e também as dinâmicas principalmente quando elas condicionam a expressão musical.

O tratamento analítico do timbre tem sua própria história que muitas vezes não é considerada nessa crítica. Antes de tudo é importante reconhecer que o timbre não é um parâmetro irrelevante. Ao contrário, muitos estudos sobre percepção e significação musical identificam o timbre como o primeiro, e muitas vezes o mais importante elemento para a identificação e apreciação musical. 
MUSICA THEORICA Revista da Associação Brasileira de Teoria e Análise Musical 2019, v. 4, n. 1, p. 62-97 - Journal of the Brazilian Society for Music Theory and Analysis@ TeMA 2019 - ISSN 2525-5541

Costumo contar uma anedota (verídica) para ilustrar o problema. Certa vez produzi um áudio de demonstração de uma partitura de minha autoria usando sons sintéticos de computador. Mostrei-o para um amigo leigo que, em resposta, fez um comentário lacônico, mas perceptivelmente depreciativo. Algum tempo depois a mesma peça foi executada e gravada por um excelente pianista. Mostrei a nova gravação ao amigo que reagiu entusiasticamente: "agora sim! Esta é uma música muito bonita, muito diferente daquela outra que você me mostrou antes!" Não adiantou argumentar que era a mesma música tocada agora por um piano. Ele se recusou a reconhecer qualquer semelhança entre as duas gravações. A percepção musical desse amigo empacava no impacto inicial do timbre.

Os etnomusicólogos que se dedicam à música indígena relatam experiências da mesma natureza. Bastos (1978) relata que ao retornar a uma aldeia que visitara anos antes, pediu ao mestre das flautas da tribo que tocasse a mesma música que ele havia gravado e transcrito na visita anterior. Como não reconhecia a música, reclamou a seu interlocutor que ele estaria tocando outra música e não a que pedira. $\mathrm{O}$ índio respondeu que era sim a mesma música, que era música de flauta o que ele tocara então e o que estava tocando agora. Ou seja, Bastos demonstra que para a cultura Kamayurá há uma identidade indissociável entre o objeto do instrumento musical, o timbre que ele produz e qualquer sequência melódico-rítmica que com ele se produza.

Entretanto, apesar dessa aparente prevalência do timbre, existe certamente a possibilidade de que ele seja superado pelos outros parâmetros. As inumeráveis transcrições entre instrumentos e as obras compostas para formações optativas comprovam essa possibilidade. Aliás, a experiência descrita acima, da comparação entre uma gravação eletrônica e outra ao piano, está relacionada com esse modo de escuta, visto que um ouvinte que ultrapassasse a percepção imediata do timbre reconheceria a identidade da "mesma música".

Uma consideração a se fazer é que o parâmetro do timbre se tornou muito importante para a música do século vinte em comparação com os períodos precedentes, tanto na música culta, como também na música comercial. Um dos motivos para isso foi a enorme expansão dos meios de produção sonora, não só devido à expansão dos grandes conjuntos orquestrais que incorporaram uma inaudita variedade de instrumentos, como também à produção de sons artificiais por meios elétricos e eletrônicos, além dos registros gravados. 
COELHO de SOUZA, R. Categorias de Análise Musical e Modelagem Física como Análise do Timbre

O foco da música moderna no timbre se radicaliza na música concreta que postula o princípio da escuta reduzida. Essa proposição realiza uma operação conceitual importante: desvincula o som, isto é, o timbre, do instrumento que o produz. Para a análise musical do timbre isso representa uma importante mudança de paradigma.

A análise tradicional do timbre é objeto da Organologia. Essa ciência é basicamente taxonômica pois estuda os instrumentos musicais, inclusive sua evolução histórica, para propor sistemas que permitam sua classificação em sistemas geralmente baseados no modo de produção do som (aerófonos, cordófonos, membranófonos, etc). Ainda que úteis, esses sistemas classificatórios têm limitações evidentes, especialmente quando se trata de analisar obras recentes em que o timbre tem protagonismo. Um exemplo simples ilustra esse problema: quando pensamos num violino, a primeira ideia que vem à mente é o som normal da corda sendo vibrada pelo arco. Entretanto, esse mesmo instrumento é capaz de produzir sons de características espectro-morfológicas muito diversas daquele, como pizzicatos, sul ponticello, col legno battuto, etc. Essas técnicas já eram usadas nos séculos anteriores. Para demonstrar a insuficiência de uma análise do timbre baseada na taxonomia dos instrumentos nem precisamos cogitar em abranger as técnicas estendidas no século vinte.

A principal dificuldade que a análise do timbre tem para superar a etapa taxonômica é que o timbre demonstra pouca propensão para organizações sintáticas. Isso significa que é difícil vislumbrar um método de análise funcional do timbre na linguagem musical. Por outro lado, o timbre sendo um atributo de qualidade sonora, se presta naturalmente a associações semânticas. Listar alguns exemplos pontuais pode ser suficiente para ilustrar essa afirmação: as castanholas significam música espanhola, o órgão significa música religiosa, a guitarra elétrica significa rock, a viola caipira significa música sertaneja, etc. Todos esses exemplos envolvem o nível semântico do signo sonoro, mas não se organizam num sistema claramente sintático, ainda que, em algumas circunstâncias, como na organização implícita da orquestra sinfônica, alguns índices de hierarquia possam ser postulados.

Houve tentativas de avançar a análise do timbre nessa direção. Embora ainda de feitio taxonômico, elas buscaram uma sistematização funcional. Um bom exemplo é o artigo de Gordon e Grey (1978) que propôs um método para se visualizar a estrutura perceptiva das modificações espectrais possíveis de se 
MUSICA THEORICA Revista da Associação Brasileira de Teoria e Análise Musical 2019, v. 4, n. 1, p. 62-97 - Journal of the Brazilian Society for Music Theory and Analysis@ TeMA 2019 - ISSN 2525-5541

produzir no som dos instrumentos orquestrais. O resultado da pesquisa resultou no método de classificação tridimensional ilustrado pela Figura 4.

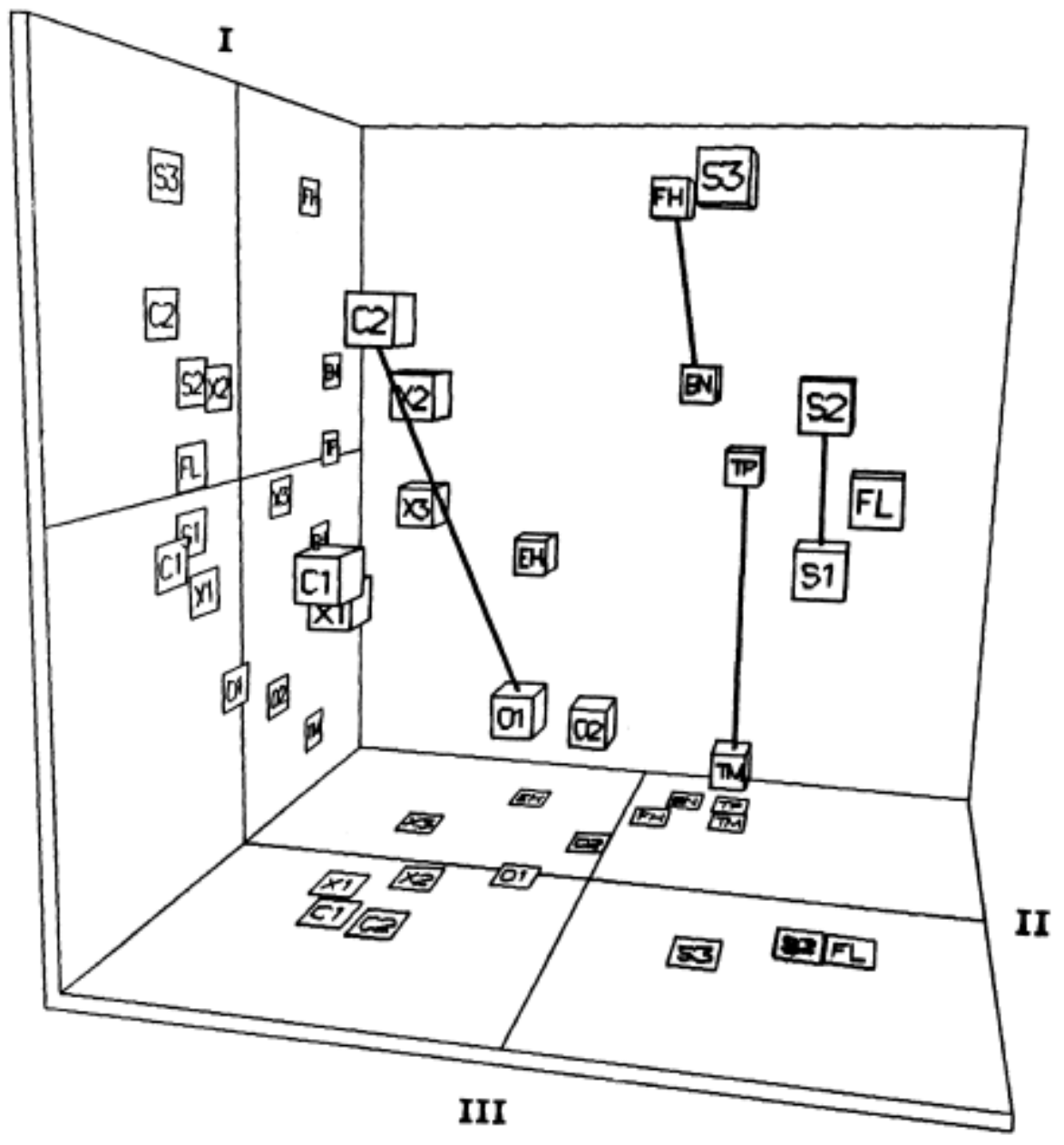

Figura 4: Representação em três dimensões da relação de timbres de 16 instrumentos: flauta (FL); 2 oboés (O1-2); 2 clarinetes (C1-2); trompete (TP); trombone (TM); 3 saxofones (X1-2-3); 3 cordas (S1-2-3); corne inglês (EH); trompa (FH) e fagote (BN). As linhas conectam pares de instrumentos que compartilham envoltórias espectrais (imagem adaptada de Gordon e Grey 1978, p. 26)

Esse tipo de pesquisa sobre o timbre, proposto quatro décadas atrás, não prosperou significativamente para se tornar um paradigma difundido. Mas um estudo de De Poli (1993), ainda nessa linha, mas através da noção de clustering, faz o link com o conceito de descritor, o qual, posteriormente, se tornou o principal paradigma na análise do timbre.

Descritores de áudio são algoritmos de análise computacional que podem ser aplicados em gravações musicais para identificar suas características acústicas, em trechos escolhidos, manualmente ou automaticamente. Essa análise 
pode coletar informações objetivas, tais como frequências fundamentais, composição espectral, aspectos dinâmicos, mas via de regra, para que se tornem úteis para a análise musical, é necessário atrelá-los a categorias perceptivas.

Existem muitos tipos de descritores, que medem certas propriedades do som, como temporais, espectrais, energéticas, harmônicas, perceptuais, etc. Os que se aplicam mais diretamente ao nosso problema são os descritores timbrísticos temporais e os descritores timbrísticos espectrais. As principais aplicações desses descritores são em classificação e recuperação de música. Como exemplos de pesquisa nessa área podemos citar o projeto jAudio do Grupo de Música e Tecnologia da Universidade McGill de Montreal no Canadá, que desenvolveu 27 descritores de baixo, médio e alto nível para extrair informações de sinais musicais. Uma descrição mais completa desse tópico pode ser encontrada em Pires (2011). Podemos também referendar o artigo de Simurra (2018) como um estudo exemplar sobre o uso de descritores para analisar timbres orquestrais. Embora não seja baseada em descritores dos tipos mencionados, o aplicativo Shazam, atualmente de propriedade da Apple, serve para o usuário identificar uma música mediante o fornecimento de um trecho gravado, com base em análise de dados espectrais, e executa tarefas semelhantes à dos descritores para informar o resultado da busca de reconhecimento. $\mathrm{O}$ aplicativo depende, porém, de um banco de dados de músicas classificadas pelas mesmas características e pelo mesmo método de análise usados na identificação da amostra fornecida.

Observa-se que todos esses processos de análise do timbre, em última instância tem propósitos taxonômicos de classificação e recuperação de informação que pertencem à primeira categoria de análise. Também apontamos acima que o timbre parece não se prestar a algum tipo de estruturação sintática que nos permita avançar para a categoria das análises funcionais. Mas, e quanto à engenharia reversa?

A possibilidade de um modelo de engenharia reversa no sentido estrito é descartada pelas nossas capacidades perceptivas. É possível treinar o ouvido para prever o resultado de uma transformação de áudio, como por exemplo: sabemos que aplicando um plugin de reverberação a uma gravação de áudio haverá aumento de volume, prolongamento da duração total, e principalmente sobreposição de características espectrais ao longo do tempo. Mas muitas vezes nem o mais treinado engenheiro de áudio é capaz de afirmar com certeza como 
MUSICA THEORICA Revista da Associação Brasileira de Teoria e Análise Musical 2019, v. 4, n. 1, p. 62-97 - Journal of the Brazilian Society for Music Theory and Analysis@ TeMA 2019 - ISSN 2525-5541

foi gerado um determinado efeito sonoro, mesmo porque a amostra pode ter sofrido múltiplos processamentos. Portanto projetar algoritmos que fossem capazes de reverter o tempo para se obter o som da fonte original é inviável.

Todavia é possível, com base em suposições bem informadas, projetar um modelo que simule computacionalmente uma fonte sonora para se estudar como determinadas fontes produzem sons. Esse processo é a modelagem, conceitualmente semelhante ao usado por Keller na peça de Xenakis, como descrito acima, com a diferença de ser aplicado aqui exclusivamente ao timbre. Propomos, em resumo, que modelagens podem ser usadas como metodologias indiretas de análise do timbre.

Um primeiro cuidado que é preciso ter é diferenciar a modelagem física da imitação de sons de instrumentos acústicos através de técnicas de síntese baseadas em modelos matemáticos clássicos. Pode-se usar a síntese de frequência modulada ou a síntese subtrativa com filtros que reduzam determinadas frequências, para simular o som de uma clarineta. Entretanto esse processo não se presta ao nosso interesse analítico porque não se preocupou com as características idiomáticas de como o instrumento produz o som. Isso pode ser o ponto chave de uma análise de timbres produzidos, por exemplo, por técnicas estendidas, que seria um caso onde a análise do timbre teria uma aplicação produtiva. Välimäki e Takala (1996) enfatizam essa diferença:

Uma diferença fundamental entre a abordagem da modelagem física e outras técnicas de síntese é que a primeira procura imitar as propriedades da fonte sonora (tipo de excitação e ressonador, ressonâncias da tampa de ressonância, etc), enquanto o foco da segunda são as propriedades do sinal sonoro percebido pelo ouvinte (forma de onda, espectro, etc). [...] As principais vantagens da síntese por modelagem física são que os parâmetros da técnica são fisicamente significantes, tais como pressão no bocal dos instrumentos de sopro e assim importantes partes da evolução dos sons (por exemplo, ataque e decaimento) são gerados automaticamente de um modo correto. (Välimäki e Takala 1996, p. 75).

Para ilustrar esta categoria de análise consideremos a pesquisa que desenvolvemos sobre a modelagem da viola caipira. $\mathrm{O}$ algoritmo de síntese do som físico é baseado na técnica das guias de onda digitais (waveguide). Buscou-se também emular algumas das importantes características do instrumento, como inarmonicidade espectral no ataque do pinçamento das cordas, resíduo de ruído devido ao choque das cordas duplas, batimento e flutuações de afinação devido às cordas duplas, controle da afinação pela pressão do dedo atrás do traste e o 
efeito da ressonância da caixa que funciona como um ressonador de Helmholtz e produz reforços das frequências formantes (vide Fig. 5).

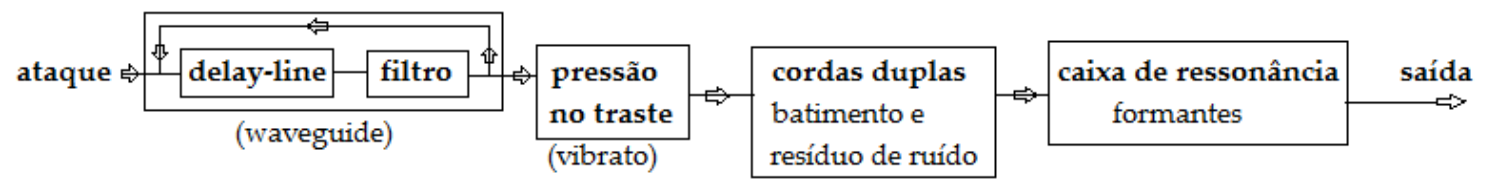

Figura 5: Fluxograma do sinal para a modelagem da viola caipira

Uma vez implementado o modelo em Csound, pode-se, por exemplo, gerar amostras de diversos modos de produção do som desse instrumento virtual com opcodes alternativos do programa e compará-las, auditivamente ou através de análise espectro-morfológica, com uma gravação de uma peça escrita originalmente para viola caipira que usou técnicas idiomáticas e expandidas do instrumento, mapeando-se assim a evolução temporal do trabalho sobre o timbre na composição da obra.

No exemplo que apresentamos a seguir, não vamos discutir os algoritmos de síntese sonora em Csound, pois nosso foco é mostrar como a modelagem dessas sínteses pode ser usada para a análise do timbre. Mencionamos apenas que usamos algoritmos de síntese da viola caipira que desenvolvemos a partir de modelos de Heintz e Lazzarini. Na tabela abaixo estão os opcodes alternativos de Csound que foram pesquisados e os respectivos parâmetros obtidos na aproximação qualitativa do som da viola caipira.

\begin{tabular}{|l|l|l|l|l|l|}
\cline { 2 - 7 } \multicolumn{1}{c|}{} & \multicolumn{5}{c|}{ opcode } \\
\hline Parâmetro & pluck & repluck & wgpluck & wgpluck2 & \multicolumn{1}{|c|}{ Descrição } \\
\hline kamp & 3000 & 12000 & - & 12000 & Amplitude \\
\hline iamp & - & - & 3000 & - & Amplitude \\
\hline kcps & p5 & - & - & - & frequência (Hz) \\
\hline icps & $(1 / 4)^{*}$ p5 & p5 & p5 & p5 & frequência (Hz) \\
\hline idamp & - & - & 2 & - & abafamento/sustentação \\
\hline ifn & 0 & - & - & - & função de decaimento cíclico \\
\hline ifilt & - & - & 90 & - & $\begin{array}{l}\text { Diminuição de duração de altas ou } \\
\text { baixas frequências }\end{array}$ \\
\hline
\end{tabular}


MUSICA THEORICA Revista da Associação Brasileira de Teoria e Análise Musical 2019, v. 4, n. 1, p. 62-97 - Journal of the Brazilian Society for Music Theory and Analysis @ TeMA 2019 - ISSN 2525-5541

\begin{tabular}{|l|l|l|l|l|l|}
\hline imeth & 6 & - & - & - & $\begin{array}{l}\text { método de decaimento natural } \\
(1, . .6)\end{array}$ \\
\hline iplk & - & 0.95 & - & 0.95 & proporção da corda (0-1) tocada \\
\hline kpick & - & 0.2 & 0.1 & 0.2 & $\begin{array}{l}\text { proporção corda (0-1) para coleta da } \\
\text { amostra }\end{array}$ \\
\hline krefl & - & 0.001 & - & 0.001 & coeficiente de reflexão (0-1) \\
\hline axcite & - & $\begin{array}{l}\text { Oscil } \\
0,1,1\end{array}$ & $\begin{array}{l}\text { Oscil } \\
0,1,1\end{array}$ & - & sinal que excita a corda \\
\hline
\end{tabular}

Tabela 1: Parâmetros usados nos opcodes alternativos de Csound visando a comparação para análise do timbre de uma amostra de viola caipira

Abaixo estão representadas graficamente a forma das ondas geradas pelo algoritmo baseado em um modelo de Heintz, utilizando os quatro opcodes (Fig. 7) e pelo algoritmo baseado no modelo de Lazzarini (Fig. 8) aplicado a um arpejo em Mi maior.

(a)

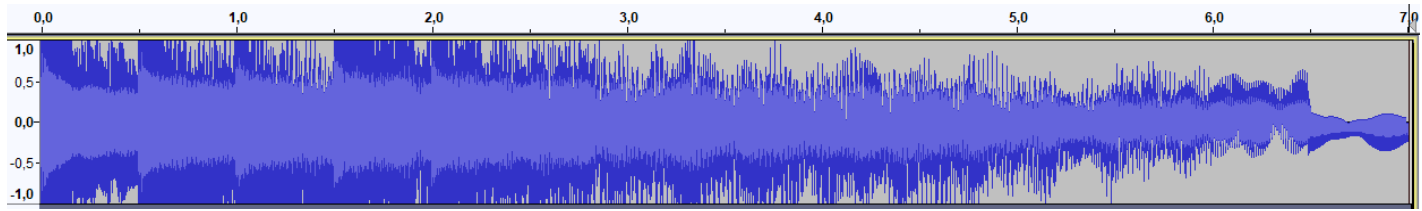

(b)

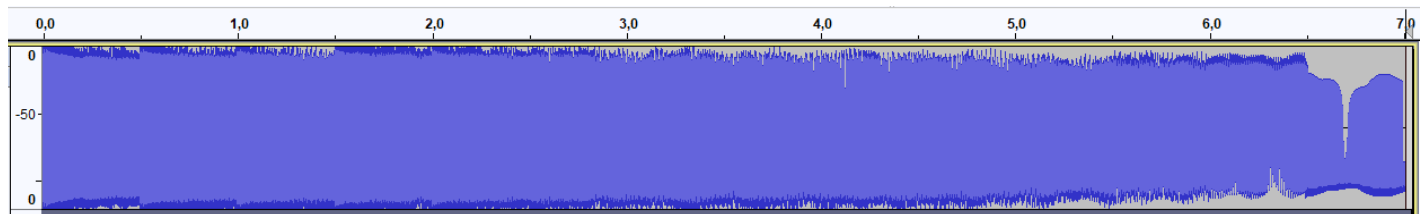

Figura 6: Sonogramas amplitude $x$ tempo de: (a) amplitude oscilando (entre -1 e 1); (b) decibéis do algoritmo Karplus-Strong de Heintz

(a) 
COELHO de SOUZA, R. Categorias de Análise Musical e Modelagem Física como Análise do Timbre

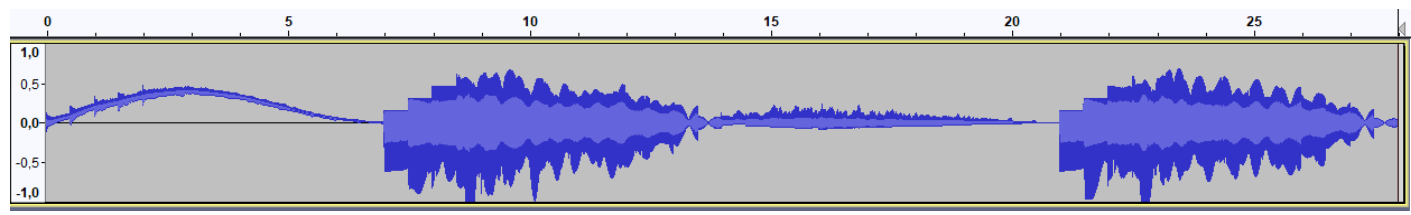

(b)

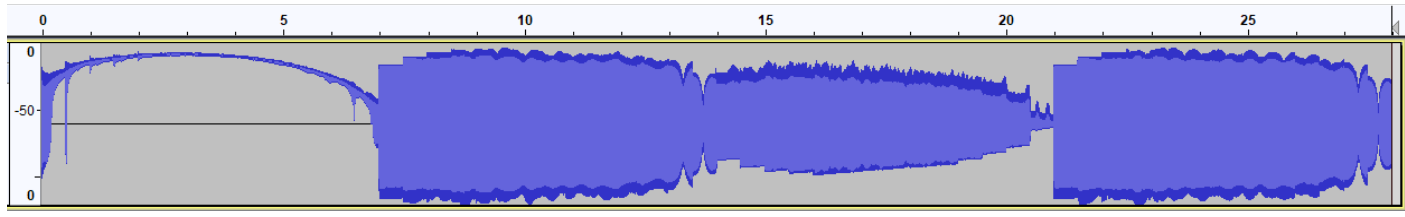

Figura 7: Sonogramas amplitude $\mathrm{x}$ tempo de: (a) amplitude oscilando (entre -1 e 1); (b) decibéis dos opcodes, usando pluck (0-7 segundos), repluck (714 segundos) wgpluck (14-21 segundos) e wgpluck2 (21-28 segundos)

(a)

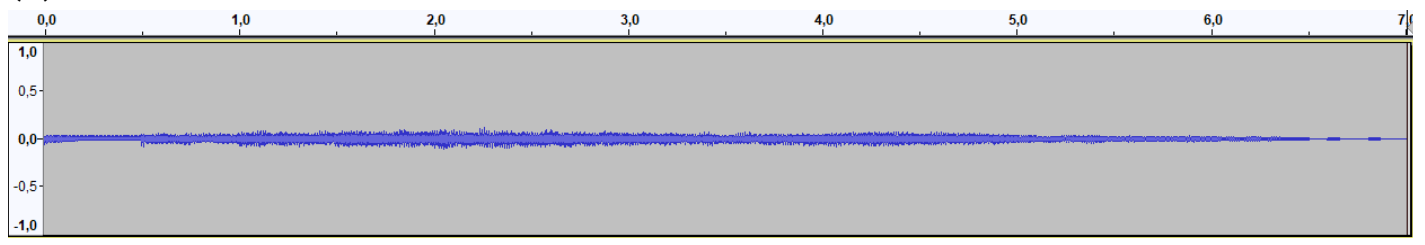

(b)

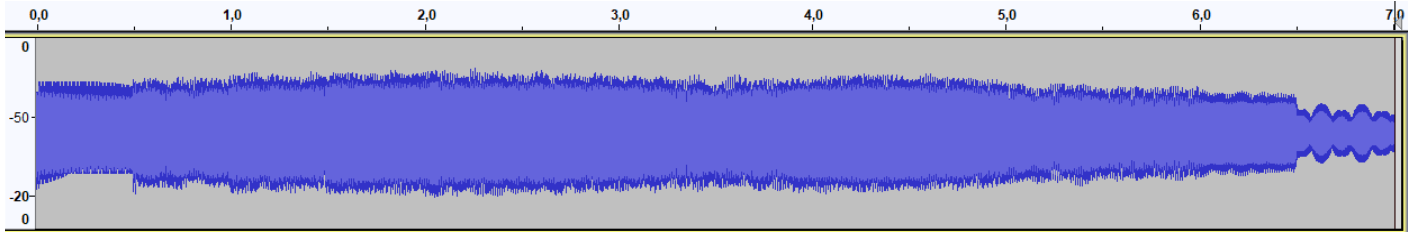

Figura 8: Sonogramas amplitude $x$ tempo de: (a) amplitude oscilando (entre -1 e 1); (b) decibéis usando o modelo de Lazzarini

Abaixo temos trechos iniciais da forma das ondas ao tocar o $5^{-}$par de cordas da viola caipira.

(i)

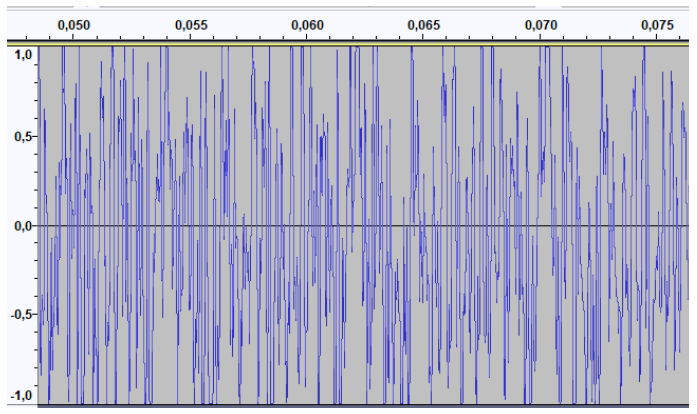

(ii)

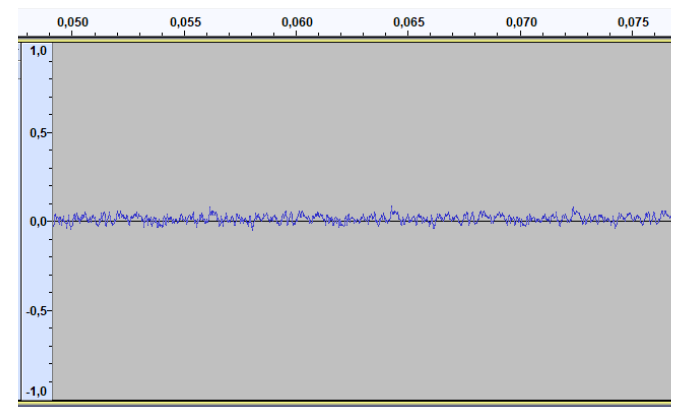


MUSICA THEORICA Revista da Associação Brasileira de Teoria e Análise Musical 2019, v. 4, n. 1, p. 62-97 - Journal of the Brazilian Society for Music Theory and Analysis @ TeMA 2019 - ISSN 2525-5541

(iii)

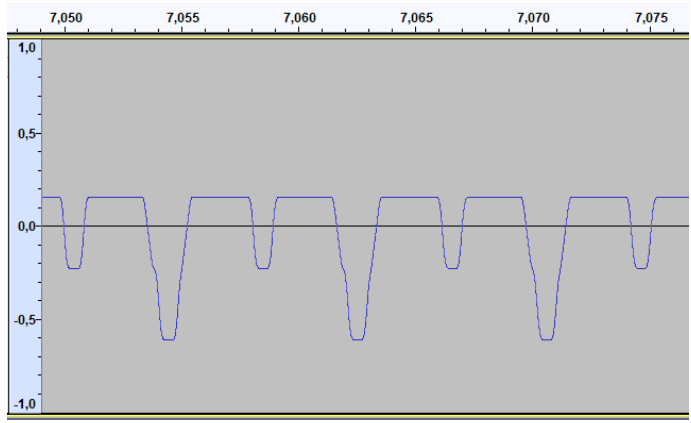

(v)

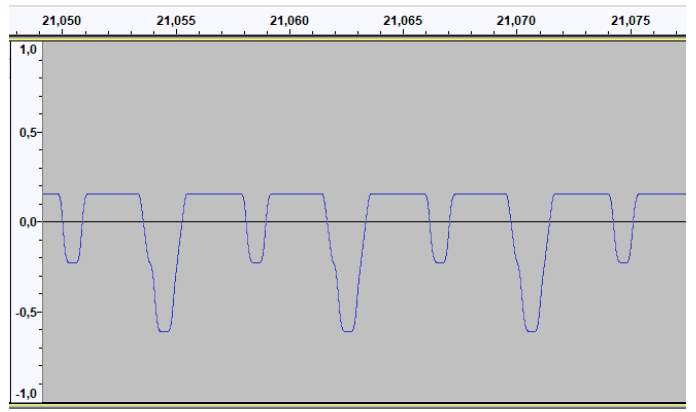

(iv)

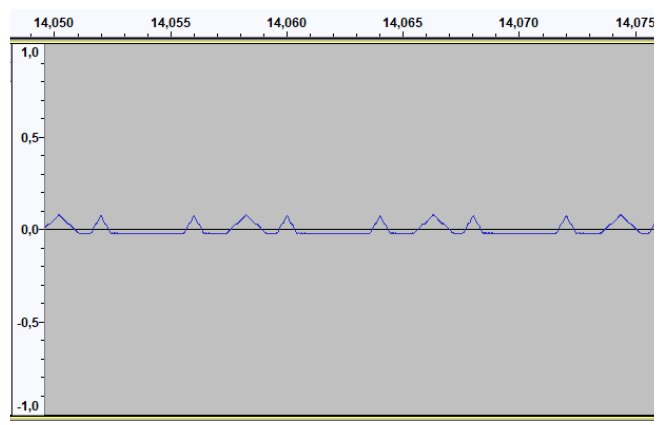

(vi)

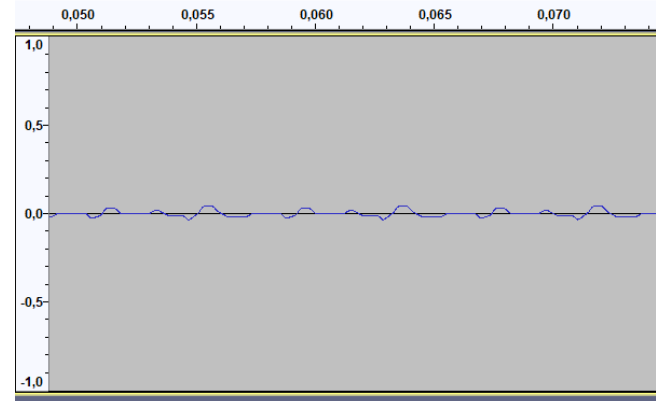

Figura 9: Trecho da forma da onda dos modelos: (i) Karplus-Strong de Heintz, (ii) pluck, (iii) repluck, (iv) wgpluck, (v) wgpluck2 e (vi) adaptado de Lazzarini

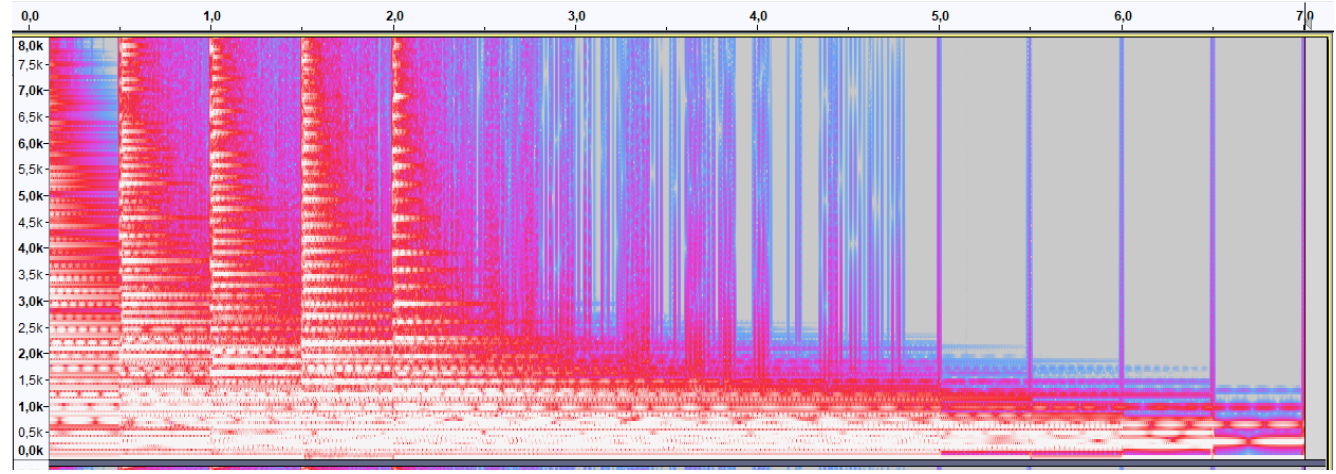

Figura 10: Espectrograma frequência $x$ tempo do modelo Karplus-Strong de Heintz

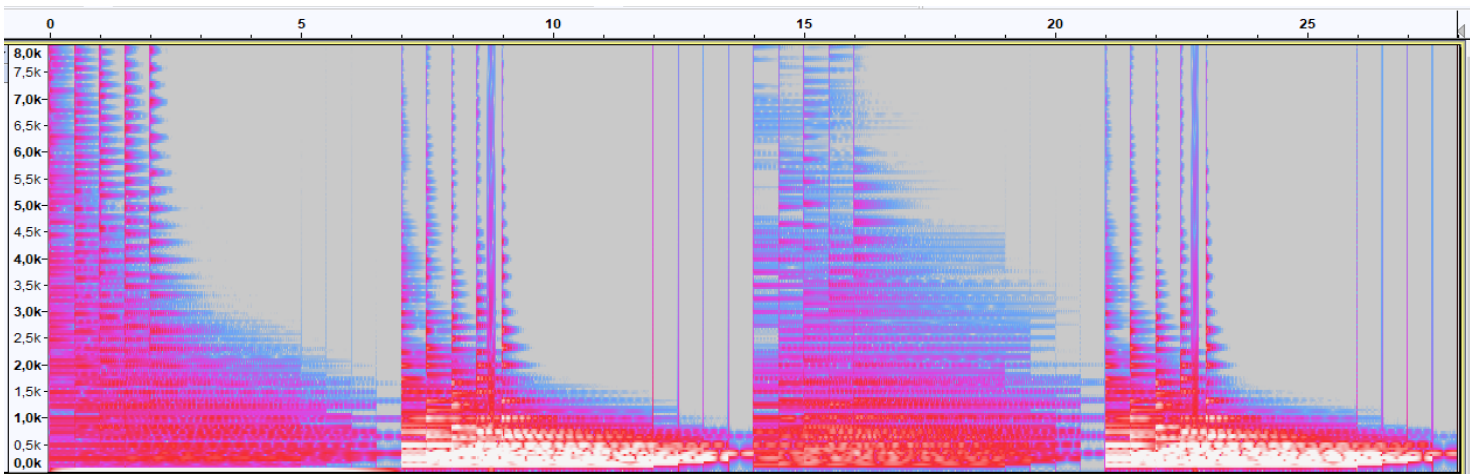

Figura 11: Espectrograma frequência $\mathrm{x}$ tempo usando os opcodes pluck, repluck, wgpluck e wgpluck2, com fenômeno de over-pluck no final das notas, conforme se observa nas linhas em 18-18,5-19 e 19,5 segundos 
COELHO de SOUZA, R. Categorias de Análise Musical e Modelagem Física como Análise do Timbre

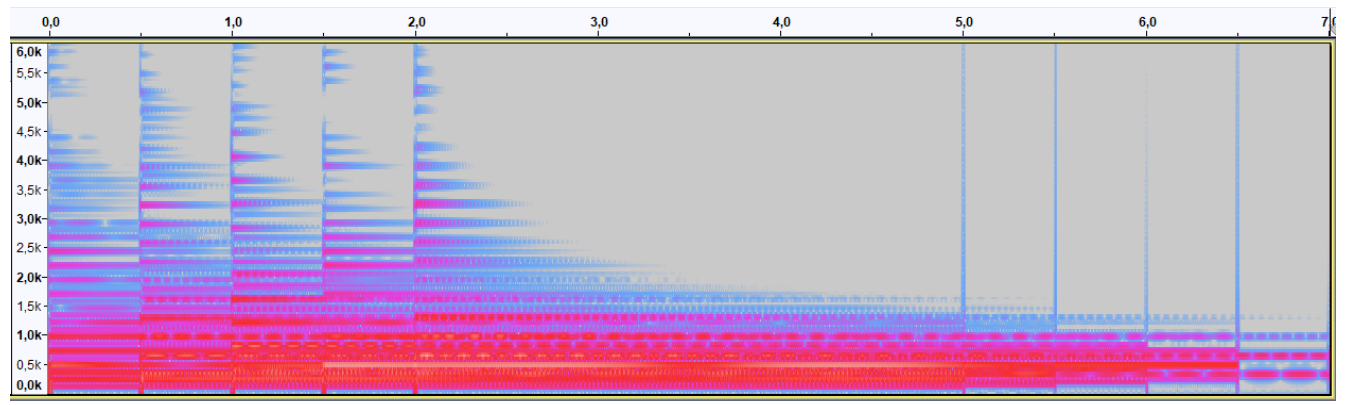

Figura 12: Espectrograma frequência $x$ tempo usando o algoritmo de Lazzarini, com fenômeno de over-pluck no final das notas

Os aspectos físicos das ondas sonoras vinculados à percepção do timbre podem ser organizados na seguinte ordem: forma da onda, amplitude e espectrograma. Deste modo, podemos comentar essa modelagem que envolve características de um sistema complexo. Em relação à forma da onda (composição de notas, efeito de batimento), com a ampliação dos fragmentos das sínteses (Fig. 9) após $0,05 \mathrm{~s}$ do início do arpejo (com o $5^{\mathrm{o}}$ par de cordas tocando) é possível observar semelhanças e distinções entre a forma das ondas entre as abordagens. O modelo de Heintz (Fig. 9i e 10) possui perfil menos regular no qual a componente de ruído se destaca em relação aos demais e sua amplitude é a maior. O perfil do opcode pluck (Fig. 9ii e 11) apresenta características similares ao anterior, com atenuação no ruído e amplitude, mostrando-se rico em componentes de maior frequência. Os opcodes repluck e wgpluck2 (Fig. 9iii e 9v) são similares em quase todos os aspectos, gerando ondas retangulares com algumas atenuações, além de ter componentes graves acentuados (Fig. 11), dificultando a modelagem do aspecto metálico da viola. O opcode wgpluck2 (Fig. 8iv) e a abordagem segundo Lazzarini (Fig. 8vi) apresentam similaridades, porém a onda gerada pelo primeiro opcode é triangular e a de Lazzarini possui algumas atenuações neste perfil. Ambas possuem componente de ruído atenuado, porém com maior distribuição em componentes harmônicas com maior frequência (Fig. 11 e 12), conferindo à modelagem uma sonoridade bem próxima à da viola caipira.

Em relação ao pluck, há a possibilidade de inserir uma maior quantidade de períodos de onda dentro da fundamental, pois icps determina o tamanho do buffer (quantidade de períodos a serem armazenados) e kcps determina o harmônico fundamental. Assim, as parciais inarmônicas geradas no ruído inicial se prolongam além do esperado para a modelagem. $\mathrm{O}$ parâmetro ifilt, existente em wgpluck, exerce um papel similar, possibilitando o controle do brilho no 
MUSICA THEORICA Revista da Associação Brasileira de Teoria e Análise Musical 2019, v. 4, n. 1, p. 62-97 - Journal of the Brazilian Society for Music Theory and Analysis@ TeMA 2019 - ISSN 2525-5541

timbre do instrumento. Acrescentamos um decaimento ao pluck para atenuar o ruído existente no final das notas sintetizadas, aqui chamado de over-pluck.

Os opcodes pluck e wgpluck, usados para uma primeira aproximação ao timbre da viola caipira, apresentaram sínteses com boa aproximação ao instrumento real, porém podem ser complementados com parâmetros adicionais. Já repluck e wgpluck2 não obtiveram a característica sonora de um instrumento com cordas metálicas, resultando em um timbre muito distante do esperado para uma síntese de viola caipira. Usado como parâmetro de uma primeira modelagem com delay lines, o modelo de Heintz apresentou muitas linhas de ruído em relação às abordagens dos opcodes e de Lazzarini. Quanto a essa última abordagem, a sonoridade corresponde ao aspecto qualitativo buscado para este estudo, assim como o pluck e wgpluck.

Em resumo, o exemplo acima demonstra como a modelagem através de processos de síntese sonora nos permite mergulhar na estrutura interna do timbre de um instrumento acústico para se obter uma compreensão analítica bastante detalhada do parâmetro timbre, bem mais completa do que seria possível somente através apenas da percepção ou da organologia taxonômica.

\section{Conclusões}

Este estudo procurou demonstrar como a Análise Musical não é um campo único, mas se serve de diversos métodos para abordar problemas específicos que obras de diferentes estilos, períodos e poéticas oferecem ao analista. Alguns desses problemas podem ser enfrentados usando-se apenas a primeira categoria de análise, que é o método taxonômico. Mostramos como as análises harmônicas tradicionais, a organologia dos instrumentos musicais e mesmo a análise pela teoria dos conjuntos de Forte encaixam-se nessa categoria. Numa segunda categoria enquadram-se os métodos que buscam uma compreensão funcional do objeto. É o caso, por exemplo das análises harmônicas riemannianas e neo-riemannianas. Essa categoria engloba uma estratégia particular que é a chamada engenharia reversa, que busca desvendar o método de produção da composição para compreender seu funcionamento. Exemplos dessa categoria são a contagem da série dodecafônica e a análise da multiplicação de Boulez na música serial. A terceira categoria é a das análises hermenêuticas que partem de estratégias heurísticas para revelar as significações, os sentidos de uma peça. As análises que empregam a teoria das tópicas e da narratividade são 
COELHO de SOUZA, R. Categorias de Análise Musical e Modelagem Física como Análise do Timbre

bons exemplos dessa categoria. Finalmente postulamos, em consonância com Keller e Ferneyhough (2004) a possibilidade de uma quarta categoria, que emprega a estratégia da modelagem. Problemas, como a estrutura de obras estocásticas e a análise do timbre, que se revelam parcial ou integralmente opacos às outras categorias de análise podem eventualmente ser tratados através dessa estratégia. Postulamos enquadrar nessa categoria a técnica da modelagem física que julgamos oferecer uma estratégia adequada para abordar a análise do timbre, seja instrumental, seja dos sons produzidos por meios sintéticos, analógicos ou digitais.

\section{Referências}

1. Bas De Haas, W.; Magalhães, J. P.; Wiering, F.; Veltkamp, R. 2014. Automatic Functional Harmonic Analysis. Computer Music Journal, v. 37 n. 4, p. 37-53.

2. Bastos, Rafael Menezes. 1978. A Musicológica Kamayurá. Brasília: Fundação nacional do Índio.

3. Bergé, Pieter (ed.). 2009. Beethoven's "Tempest" Sonata: Perspectives of Analysis and Performance. Leuven: Peeters.

4. Cope, David. 2005. Computer Models of Musical Creativity. Cambridge, MA: The MIT Press.

5. Dahlhaus, Carl. 1989. Nineteenth-Century Music. Berkeley: University of California Press.

6. De Poli, Giovanni, Paolo Prandoni e Paolo Tonella. 1993. Timbre Clustering by Self-organizing Networks. Milão: Proceedings of X Coloquium on Musical Informatics, p. 102-107.

7. Gordon, John W. e John M. Grey. 1978. Perception of Spectral Modifications on Orchestral Instrument Tones. Computer Music Journal, v. 2, n. 1, p. 24-31.

8. Guck, Marion. 1994. Analytical Fictions. Music Theory Spectrum, v. 16, n. 2, p. 217-230.

9. Hanninen, Dora. 2012. A Theory of Music Analysis: on Segmentation and Associative Organization. Rochester: University of Rochester Press.

10. Hatten, Robert S. 1994. Musical Meaning in Beethoven: Markdness, Correlation, and Interpretation. Bloomington: Indiana University Press.

11. Keller, Damián e Brian Ferneyhough. 2004. Analysis by Modeling: Xenakis's ST/10-1 080262. Journal of New Music Research v. 33, n. 2, p. 161-171. 
MUSICA THEORICA Revista da Associação Brasileira de Teoria e Análise Musical 2019, v. 4, n. 1, p. 62-97 - Journal of the Brazilian Society for Music Theory and Analysis@ TeMA 2019 - ISSN 2525-5541

12. Koblyakov, Lev. 1990. Pierre Boulez a world of harmony. New York: Routledge.

13. Krämer, Thomas. 1997. Lerhbuch der harmonischen Analyse. Wiesbaden: Breitkopf \& Härtel.

14. Křenek, Ernst. 1940. Studies in Counterpoint. New York: Schirmer.

15. Lerdahl, Fred. 2001. Tonal Pitch Space. New York: Oxford University Press.

16. Lerdahl, Fred; Jackendoff, Ray. 1983. A Generative Theory of Tonal Music. Cambridge, MA: The MIT Press.

17. Lewin, David. 2007. Musical Form and Transformation: Four Analytic Essays. Oxford: Oxford University Press.

18. Pires, André Salim. 2011. Métodos de Segmentação Baseados em Descritores Musicais. Dissertação de Mestrado. Instituto de Matemática e Estatística da Universidade de São Paulo.

19. Rehding, Alexander. 2003. Hugo Riemann and the Birth of Modern Musical Thought. Cambridge: Cambridge University Press.

20. Riemann, Hugo. 1874. Musikalishe Logik. Leipzig: C. F. Khant.

21. Roads, C.; Wieneke, P. 1979. Grammars as Representations for Music. Computer Music Journal, v. 3, n. 1, p. 48-55.

22. Schönberg, Arnold. 1963 (ed. original, 1951). El Estilo y la Idea. Madrid: Taurus.

23. Schmalfeldt, Janet. 2011. In the Process of Becoming. Oxford: Oxford University Press.

24. Simurra, Ivan E. 2018. Análise Musical Assistida por Descritores de Áudio: um estudo de caso da obra Reflexões de Jônatas Manzolli. Revista Musica Theorica, v. 3, n. 1, p. 33-67.

25. Straus, Joseph N. 2009. Twelve-Tone Music in America. Cambridge: Cambridge University Press.

26. Välimaki, Vesa e Tapio Takala. 1996. Virtual Musical Instruments - Natural Sound Using Physical Models. Organised Sound, v. 1, n. 2, p. 75-86.

27. Versolato, Júlio César. 2008. Rumos da Análise Musical no Brasil: Análise Estilística 1919-84. Dissertação de Mestrado. Instituto de Artes da Universidade Estadual Paulista. 